Illinois State University

ISU ReD: Research and eData

Theses and Dissertations

4-1-2019

\title{
The Use Of Discursive Features As A Representation Of Voice And Identity In L2 Writing: A Case Study Of Multilingual Graduate Students
}

Demet Yigitbilek

Illinois State University, demet.yigitbilek@gmail.com

Follow this and additional works at: https://ir.library.illinoisstate.edu/etd

Part of the Bilingual, Multilingual, and Multicultural Education Commons, and the Linguistics Commons

\section{Recommended Citation}

Yigitbilek, Demet, "The Use Of Discursive Features As A Representation Of Voice And Identity In L2 Writing: A Case Study Of Multilingual Graduate Students" (2019). Theses and Dissertations. 1084. https://ir.library.illinoisstate.edu/etd/1084

This Thesis is brought to you for free and open access by ISU ReD: Research and eData. It has been accepted for inclusion in Theses and Dissertations by an authorized administrator of ISU ReD: Research and eData. For more information, please contact ISUReD@ilstu.edu. 
THE USE OF DISCURSIVE FEATURES AS A REPRESENTATION OF VOICE AND

IDENTITY IN L2 WRITING: A CASE STUDY OF MULTILINGUAL GRADUATE

STUDENTS

\section{DEMET YİĞİTBİLEK}

\section{Pages}

Considering the constant increase in the number of international students studying in the US universities, it is important to address the issue of self-representation in writing as there are classrooms where students are still assumed to be native English speakers by default (Matsuda, 2006). Therefore, academic writing practices of multilingual writers can easily be seen as divergences from the 'standard' rather than conscious acts. However, since languages are at the core of who we are (Anzaldúa, 2001), how we use our linguistic repertoires in writing should be seen as representation of our multilingual and diverse identities. This thesis, then, presents the results of a series of interviews with three multilingual graduate students and the textual analyses of their academic writing samples by focusing on how their experiences in writing in other languages, in different contexts and genres shape their linguistic choices in how they represent their multilingual and multifaceted identities. The results of the study reveal that these multicompetent writers (1) negotiate their disciplinary voices through predominantly their linguistic and thematic choices in their academic writing practices, (2) use multiple ways of argumentation in the academic texts they produce which are heavily influenced by their linguistic and cultural backgrounds as well as in and out-of-school context interactions, (3) integrate personal experiences and/or narrative style in their argumentation in their academic 
texts as a way to exert their in-between identities as scholars and international graduate students. The findings have implications for both institutional spaces and instructional support for multilingual writers across disciplines as they help us better understand the decision-making processes of these resourceful writers in terms of lexical, syntactic, and rhetorical choices as they have unique ways of saying 'I'm here'.

KEYWORDS: voice and identity; L2 writing; multilingual writers; discursive features 
THE USE OF DISCURSIVE FEATURES AS A REPRESENTATION OF VOICE AND IDENTITY IN L2 WRITING: A CASE STUDY OF MULTILINGUAL GRADUATE STUDENTS

DEMET YİĞİTBİLEK

A Thesis Submitted in Partial Fulfillment of the Requirements for the Degree of

MASTER OF ARTS

Department of English

ILLINOIS STATE UNIVERSITY

2019 
(C) 2019 Demet Yiğitbilek 
THE USE OF DISCURSIVE FEATURES AS A REPRESENTATION OF VOICE AND IDENTITY IN L2 WRITING: A CASE STUDY OF MULTILINGUAL GRADUATE STUDENTS

\section{DEMET YİĞİTBİLEK}

COMMITTEE MEMBERS:

Lisya Seloni, Chair

Joyce Walker 


\section{ACKNOWLEDGMENTS}

I'd like to extend my gratitude to firstly my committee, Dr. Lisya Seloni and Dr. Joyce Walker. I feel so blessed to have met you in my first semester and having worked with you afterwards leading up to this project. It wouldn't have been possible for me to feel this connected to it without your open-mindedness and never-ending support and encouragement. So, thank you immensely my lovely role models!

I've had the love, care, and endless support from my family, especially my mom, throughout this process, and even though we've been miles apart, her pure existence in my life gives me the strength to always move forward. Thank you mom for being the way you are, you magical creature from fairy tales!

And all my friends, both from Turkey and ISU, who have endured my non-existence and occasional appearances in their lives. Thank you for still keeping me in your lives and listening to my naggings about me learning to navigate in this world!

Last but not least, thank you Shane for being my favorite story-catcher. Your existence means the world to me.

Grateful for all of you!

D.Y. 


\section{CONTENTS}

Page

ACKNOWLEDGMENTS

TABLES

CHAPTER I: INTRODUCTION 1

CHAPTER II: REVIEW OF LITERATURE $\quad 8$

$\begin{array}{ll}\text { Introduction } & 8\end{array}$

Multiple Identities and Their Negotiation in Different Social Contexts $\quad 8$

Identity Representation Through Discursive Voice 11

Positioning of the Self in Writing 13

$\begin{array}{ll}\text { CHAPTER III: METHODOLOGY } & 18\end{array}$

$\begin{array}{ll}\text { Introduction } & 18\end{array}$

$\begin{array}{ll}\text { Case Study Research } & 21\end{array}$

Case Studies of Graduate Writers: Textual Analysis of Writing in L2 22

$\begin{array}{ll}\text { My Study } & 26\end{array}$

$\begin{array}{ll}\text { The Context } & 26\end{array}$

$\begin{array}{ll}\text { Participants } & 27\end{array}$

$\begin{array}{ll}\text { Data Sources } & 30\end{array}$

$\begin{array}{ll}\text { Data Collection } & 31\end{array}$

$\begin{array}{ll}\text { Data Analysis } & 32\end{array}$

$\begin{array}{ll}\text { Limitations of My Study } & 34\end{array}$

CHAPTER IV: RESEARCH FINDINGS

$\begin{array}{ll}\text { Introduction } & 37\end{array}$ 
Orsi: 'The person in the essay is who I wish I could be in real life'.

Complex Identity Performances $\quad 38$

'Humble Passive Activist' Writer Identity 43

$\begin{array}{ll}\text { Writer Positionality } & 45\end{array}$

Writing Sample: Ideational and Interpersonal Evidence $\quad 47$

Murat: 'I am half-professional, half-storyteller' 55

Moving Between Languages $\quad 55$

Linguistically Aware Writer Identity 55

$\begin{array}{ll}\text { Writer-Researcher Positionality } & 63\end{array}$

Writing Sample: Ideational and Interpersonal Evidence $\quad 67$

Abigail: 'We are constrained by the language we use.' 72

'Because of the unconfidence' $\quad 72$

$\begin{array}{ll}\text { Reader Conscious Writer Identity } & 75\end{array}$

Writing Sample: Ideational and Interpersonal Evidence $\quad 78$

$\begin{array}{lr}\text { Common Themes in All Three Cases } & 88\end{array}$

CHAPTER V: PEDAGOGICAL IMPLICATIONS 96

$\begin{array}{ll}\text { Introduction } & 96\end{array}$

Overview of Findings in Light of Existing Research 96

$\begin{array}{ll}\text { Pedagogical Implications } & 100\end{array}$

$\begin{array}{ll}\text { Institutional Instructor Support } & 102\end{array}$

$\begin{array}{ll}\text { Instructional Support } & 113\end{array}$

$\begin{array}{ll}\text { REFERENCES } & 124\end{array}$

APPENDIX A: PRE-INTERVIEW SURVEY 132 
APPENDIX B: FIRST INTERVIEW QUESTIONS

APPENDIX C: SECOND INTERVIEW QUESTIONS

APPENDIX D: FACULTY RESOURCES FOR MULTILINGUAL GRADUATE STDUENT

WRITING

139 


\section{TABLES}

Table

Page

1. Overview of Participants 


\section{CHAPTER I: INTRODUCTION}

Considering the constant increase in the number of international students preferring to study in US universities (IIE report, 2017) for their graduate degrees, it is important to address the issue of self-representation in writing as there are classrooms where the students are still assumed to be native English speakers by default (Matsuda, 2006). Therefore, academic writing practices employed by multilingual and multicompetent writers, such as myself, can be seen as divergences from 'Standard English' or even as deficiencies rather than a means for selfrepresentation. However, since languages are at the core of who we are (Anzaldúa, 2001; Casanave 1992, p.165 in Hirvela and Belcher, 2001, p.86), how we use our linguistic repertoires in writing should be seen as representation of our multilingual and diverse identities.

With these ideas in mind, the goal of this thesis is to investigate and understand how graduate multilingual writers in the US higher education write in their disciplinary courses. In that sense, the study mainly focuses on these students' academic writing practices in English in their disciplines and how their prior experiences in writing in other languages and in different contexts and genres shape their linguistic choices with regards to their representations of their multilingual and multifaceted identities and voices.

As an international Master's student focusing on TESOL and Linguistics, I would like to start with my own linguistic adventure to give the reader an understanding about what literate practices are usually involved in the academic life of a multilingual person learning languages to write in order to communicate in academic discourses. Studying in an English-medium university has given me the linguistic resources and provided me with the opportunities to be able to join the conversations 'in the center' as a scholar 'in the periphery' (Canagarajah, 2002), 
but I have also faced some limitations as crossing boundaries in writing in academic English in my EFL context was at times challenging during my studies.

I started learning English in a foreign language context, in Turkey, in primary school language courses, but it was not until I started studying in an English-medium university that I began writing more than a couple sentences in English. But even then, the first and the only type of writing I learned to write in was 5-paragraph-essay format, heavily loaded with an unfamiliar academic style, far from reflecting personal voice, and not allowing expressions of my identity as a multilingual writer as experimenting with this second language writing in different genres and text types other than exposition and argumentation was something that was missing in my training. I could not put pieces of myself or make my voice visible in a way I would have liked to because that was not the way to go if I wanted to pass the proficiency exams, which do not actually assess one's ability to use language creatively but rather focus on seeing the imitation of similar essays written in academic English. In retrospective, this common practice was limiting the way my identity could have been better reflected in my writing as writing provides a space for identity representation in different forms. However, the singularity observed there ignored all the other possibilities of how to present my own identity as a writer in English, in my own unique voice, and led me to make peace with imported ways of writing both in the exams as well as in the writing assignments within my discipline. However, the nagging felt sense I have had ever since has led me to think about other possible ways of self-representation in academic writing that I might be missing. Therefore, I began my research journey with two primary questions: (1) How do multilingual students, like myself, can and do negotiate different aspects of their identities in their academic writing practices?, and (2) What are some of the linguistic acts they make use of in disciplinary writing as a way of representing themselves?. 
As in the case of many EFL contexts, such as China (You, 2004), the singularity of using one style of writing has been the result of adaptations to imported Western writing pedagogies, without taking into account the local contexts. For me, I had to use certain structures, be clear and not use metaphors, or similes, or any other language art, which are highly appreciated in a writing piece in my first language while writing in literary genres, which were the types of writing I was familiar with. Transferring my existing writing skills in literary genres, where I was more able to use my own voice represented through the linguistic choices I could integrate into this new language seemed to be out of the question if I wanted to be 'successful' in English academic writing- which seemed to focus on only the versions of the 5-paragraph essay. The sociolinguistic realities of English, in my case, along with existing educational traditions, thus led to situations where my existing writing experiences were excluded from my process of learning to write in English. As in other EFL contexts, relying heavily on 5 paragraph essay has been due to the fact that teaching writing is a part of the English language courses and therefore requires different approaches than ESL contexts (Ortega, 2009).

The underlying and highly complex reasons for writing instructors to follow a traditional and task-based or product-oriented instruction may vary in different contexts (You, 2004), including the sociopolitical and economic forces and the dynamic nature of writing practices in foreign language contexts as they relate to inherently changing social conditions and educational factors influencing both teaching policies and practices as well as teacher education (Flowerdew and Li 2009; Reichelt, 2009; Ortega, 2009; Rinnert and Kobaysahi, 2009; Casanave, 2009; Sasaki 2009; Manchón \& de Haan, 2008).

So, in my experience, I tried to put my existing knowledge of writing aside and worked to acquire a new writer identity for academic writing in my L2 English. As part of my acceptance 
of these complex dynamics, I have come to acknowledge the fact that there is more to academic writing than just 5 paragraph essay and different ways and levels of exerting my voice. This can be achieved through the linguistic moves one can exert in any type of writing in varying levels to be able to own the text- even in academic discourses which are usually seen as impersonal.

I have started this research journey from a graduate student perspective, which is obviously due to my position in the world at this point as a graduate student navigating the world of academia in the United States. As an international female graduate student, who has studied in an English-medium university in Turkey, a country English is taught as a foreign language and seen as a ticket to success in academy, as a former English language assistant and Turkish culture representative who taught in Spain, another country where English is a foreign language, and as an English language teacher at the university level having worked with a lot of students with diverse linguistic and educational backgrounds, I can say that I have seen changing identities at play in how students, like myself, write, in any language or variety they already have or any language they are learning. I have had students who came up to me with questions about their essays where I had marked up with question marks as I didn't see their topic sentences at the beginning of their paragraphs or with arrows to re-organize their sentences or paragraphs as they were not in the 'right' place according to English writing style that we were teaching as 5 paragraph essay. I remember thinking to myself 'Why can't they just write the way I want them to? Why the resistance to the rules I provide?', not fully aware of what was happening- that they were trying to write their way, that they were trying to say 'This is who I am and this is how I write. This is the way I've learned how to write [in high school or in Turkish literature courses or in other genres] and this is the way I want to include me in this writing, as well [putting in my ideas in the way I feel more comfortable- maybe stating my idea at the end of a paragraph or not 
even saying it directly but just implying it and leaving it to the reader to figure out my stance].' As my students were transitioning from high school to university, from Turkish-medium instruction to English-medium academic writing, their questions as to what writing means and how they can retain their writer identities while still conforming to the rules and conventions of this new writing system led them to reconsider who they are or who they want to be if they wanted to continue become successful students and good writers. Having been in the same situation myself as a student, and unlike them, as someone who did not question the ways I was presented as the new ways of writing [in English] since it was the ticket to success, it took me years to reconsider my responses to these students. Finally, my existing approaches to teaching academic writing started to fail and I could no longer find efficient responses to my students' resistance to change their ways of self-representation in writing as they were not as conforming as I was when I was in their position. Then arose my desire to explore different academic writing practices, especially for those who already have experienced writing in different languages, different styles, and different genres to see how they might influence their writing in unfamiliar situations. As I became a graduate student, moved across the world and changed my whole life and my immediate context, my social life, I realized some changes in me. I was no longer only a teacher but also a student, now. I was no longer a language instructor to speakers of other languages but a writing instructor to native speakers now. Having realized that I, too had multiple identities and social roles and responsibilities led me to think about how these factors influence the way $I$ write in this new context as these are the day-to-day challenges my students were also facing- which I failed to see at the time.

My story might sound familiar even though it took place, and still continues to take place in an expanding circle country (Kachru, 1985), an EFL context, where students learn to write 
academically mostly at college level and mostly if they are studying in an English-medium university. Learning and teaching of English as a foreign language is highly influenced by the various local sociohistorical, educational, and political factors (Reichelt, 2009), as mentioned earlier, and importing foreign pedagogies without proper adaptations to fit to the local context proves unsuccessful in many senses, especially considering the fact that even present social conditions are also dynamic and in constant change making writing practices ever-changing, as well (Rinnert and Kobayashi, 2009). To make the matters more challenging for practitioners, these situational variables also affect the motivational level and attitudes of the students learning English in these contexts towards L2 writing (Rinnert and Kobayashi, 2009; Sasaki, 2009). Therefore, the diverse nature of foreign language writing (Flowerdew and Li, 2009) needs to be emphasized when considering the teaching and learning of writing practices in EFL contexts as they provide great insight into what additional factors go into the learning of writing in an additional language where that language is not the dominant one. In this regard, students learning English in these foreign contexts tend to rely on their prior experiences with writing, both in their L1 and their L2 Englishes, and such reliance of these multilingual L2 writers' on various languages at their disposal while composing in English (Celaya and Navéz, 2009) requires a different perspective in research in L2 writing as L1 and L2 seem to be at play continuously at the cognitive level (Manchón, De Larios, Murphy, 2009) while these students are composing a text since they already have prior experience in writing in their L1. With these bilingual or multilingual writers, according to the multicompetence theory (Cook 2002; 2008), there is, in fact, a hybrid system of linguistic knowledge that overlaps at the cognitive level, and this system is not static or fixed yet it changes through experience as they add to their linguistic repertoires. 
Consequently, in L2 writing instruction, there should be room to recognize this hybridity, this shared writing knowledge across languages, across genres, and styles.

Not being able to appreciate my linguistic repertoire in my home country, and failing to recognize the linguistic acts of my students that were signs of self-representation and selfpositioning in the texts, I have come to US for graduate school; a context where the imported writing instruction I was exposed to originated. However, even though the academic writing instruction has started to make more sense here, and I have started to position my voice better in my writings in my disciplinary courses, I am, at this point, still not so sure how much of my multilingual identity is represented as an international graduate student in this 'inner circle country' (Kachru, 1985). Yet, my endless curiosity in understanding the self in writing carries me to new paths, such as this research project, that I do not regret adventuring into. 


\section{CHAPTER II: REVIEW OF LITERATURE}

\section{Introduction}

In an effort to explore in depth the daily encounters of negotiation of identities and how they are demonstrated through speech or writing, I have begun my research on multilingual graduate writers. I can say that my scholarly experiences and growth as a multilingual graduate student in my journey so far as well as my challenged and challenging experiences as an English language teacher have paved the way for my research into the multiple identity aspects and their influences in the way multilingual and multicultural individuals negotiate their selves in different social contexts as well as the linguistic moves they make use of in writing, especially in academic writing, in different disciplines. As certain identity aspects are changing as we move from being an undergraduate student to being a graduate student, and even more so if we are moving from one context to another, one country to another, or from one discipline to another, from one language to another, the need to recognize the shifts in writing practices seems important to explore. To this end, in an effort to see different acts of self-representations in multilingual writers' academic writing practices and to better understand the underlying factors influencing the linguistic choices, this study, therefore, analyzes the composing processes of three international graduate students creating academic texts in their disciplines.

\section{Multiple Identities and Their Negotiation in Different Social Contexts}

The postmodern notion of identity claims that multiple identities that individuals have are fluid, complex and multifaceted (Bakhtin 1981, Bourdieu 1977, Cummins 1996, Pierce 1995, Weedon 1987, West 1992 in Nero, 2005, p.194), and complicates the matter of diversity in societies further. Every utterance individuals make reflects 'a profession, a genre, a tendency, a 
party, a particular work, a particular person, a generation, an age group, the day and hour' (Bakhtin, 1981, p.293 in Prior, 2001) which is an image of the 'socially charged life' (Prior, p.70) and the context(s) in which the utterance takes place. In that sense, every utterance includes a representation of a combination of multiple identity aspects. However, throughout US history of education, there has been an attempt to do away with the differences in the society based on the belief that unity brings harmony while diversity brings 'instability and discord' (Nieto, 2004, p. 145). On the other hand, in line with the fact of increasing diversity, it is irrational to consider individuals possessing only one type of identity. Depending on the social roles we assume within the groups we belong to, we demonstrate various identities as a response to the demands of changing situations around us. In that sense, we have varying voices, and as also Halasek (1999) argues, voice is a multiple medium that comes into being by combining different selves (Hirvela and Belcher, 2001, p. 90). Therefore, we should look into the concept of voice and identity from a plural perspective (Hirvela and Belcher, 2001). To this end, it is significant to observe that every word can mirror multiple voices (Prior, 2001). Consequently, as we engage in various social practices in which we organize and represent our identities while positioning ourselves in a diverse environment, our positionings are inevitably reflected in the way we use language. As Norton (2010) states, language is a social practice where experiences are organized and identities are negotiated. Therefore, as societies change, the language use also changes over time and space; and people become 'multimembers' in different communities (Norton, 2010, p.355), having multiple and intersecting identities in terms of race, gender, class, and sexual orientation, which may impact their language learning process. Having such intersections, then, creates a diversity of voice-related issues as each individual has a different combination of such aspects of their identities and they engage in different identity representation acts, which also manifests 
itself in the language use both in spoken and written form. That is why, there is a need for a multicultural perspective in education, and consecutively writing instruction that affirms not only sociocultural but also individual differences rather than simply denies them or categorizes people based on only socially constructed boxes per different aspects of identities.

When addressing the issue of voice in language use, Hirvela and Belcher (2001) argue for the use of voice as an interpretive and analytic device, especially in regards to L2 contexts. In their study, they looked at the struggles of NNES graduate students' in trying to find their voices in 'academese' (p.86) and analyzed these students' utterances in terms of self-representation and identity as revealed by the 'voicist terms' (p.84) they used. Since these mature graduate students differed also in terms of their disciplines, their native languages and cultures, and their antecedent academic and professional writing experiences, they showed a variety also in terms of their voice-related issues observed. Their study, in that sense, serves as a confirmation that these individuals already have their voices, identities and self-representations in their L1s and that they indeed already have a writerly identity, but their struggles in negotiating those identities in L2 English, and especially in academic writing, differs and this diversity is multilayered as one creates or adds another voice and identity when they write in another language, and in another style such as academic writing, yet this does not mean that they lose certain aspects of their identities, but rather, there is a negotiation and adapting process taking place to meet the needs and demands of the new writing situations. Therefore, we should see writing, and teaching and learning of a language, as an activity (Prior, 2001) that includes 'political, social, and ethical responsibilities for (re)making ourselves and our worlds that we cannot elide, that we should be aware of and decide how to address.' (p.78) (emphasis mine). Therefore, I aim to further explore the effects of this phenomenon, not just within the area of second language learning, but also in 
teaching of writing and composition as these spaces are also discourses where multiple negotiations of voice and identity can be observed.

\section{Identity Representation Through Discursive Voice}

There is a great deal of focus in the field of second language writing on 'normative aspects' in written discourse (Matsuda, 2001, p. 36); however, the influence of individual variations as reflected in divergent discourse practices proves at least as much important yet has been neglected until recently. When individuality emerges in the discussion of L2 writing, the notions of voice and identity as represented in written discourse requires closer investigation due to the fact that understanding how writers compose texts and make their voices and identities a part of their writing provides useful insights for writing instructors dealing with students who have been writing in different languages and engaging in varying discursive acts in various genres. Every language can demonstrate proof of voice as reflected by the writer writing in that language making individual choices; however, 'the ways in which voice is constructed are not universal; different languages provide different possibilities for the construction of voice because, while many linguistic features are available across various languages, some are not.' (Matsuda, 2001, p.40). In that sense, dealing with 'discursive identity' is more challenging when the writer and the reader of a written text are familiar with different discursive practices as dependent on their linguistics backgrounds- languages in which they write (Matsuda, 2001, p. 39) as each language shows unique features for the writers in that language who construct their identities and voices in their writing. This kind of unfamiliarity poses challenges for writing instructors who are not familiar with the discursive features of their (multilingual) students' languages and thus assess their writing in English as ineffective. 
Matsuda and Tardy (2007), in their study where they asked two reviewers to conduct a blind review for a manuscript, a high-stakes academic writing of a graduate student, describe discursive features as involving both form, such as sentence structures, organization, the use of transition devices, word choice as well as content, including the choice of topic and specific examples, and argumentative strategies. In addition, non-discursive textual features may also be involved, including, for example, the use of margins, the choice of font face and size, the use of blank space between words and punctuation marks as well as the use of extra line-breaks between paragraphs and block quotes. They emphasize that the use of such features gives certain impressions to the reader in terms of the identity of the writer through their representations of their voice revealed by the way they make use of such features in their writing. Therefore, it is safe to say that these linguistic behaviors as a representation of identity show individual variations in discursive and non-discursive practices. Their study indicated that readers (reviewers in this case) construct an author identity and voice based on what they read, showing evidence for their impressions, which suggests that 'voice as self-representation is inevitable not only in writing, but also in all human activity’ (Ivanic and Camps, 2001, p.4). This study also provides significant input in the sense that the readers were able to form impressions of the author's identity and voice through their reading of the manuscript- an academic writing which is regarded as a 'less personal' type of writing (p. 241), confirming that voice is still observable even in this style of writing, which is evident through discursive decisions that the writer made, giving clues and impressions to the readers making it possible for them to form opinions on the author being 'novice' and 'male' (p.241). Therefore, Matsuda and Tardy suggested, these various features in writing, and 'by extension, voice' (p.246) is shared by the readers, which makes the process 'interpersonal' (Ivanic and Camps, 2001). 


\section{Positioning of the Self in Writing}

Positioning in writing has been investigated by several scholars in L2 writing. For instance, what Ivanic and Camps (2001) mean by this is related to their identification of writer's positioning in writing, which they base on Halliday's (1985) macrofunctions of language: ideational positioning, interpersonal positioning, and textual positioning. These three types of positioning respectively relate to what the writer is talking/writing about, how they are interacting with the reader, and how they are shaping the text, and writers can show signs of struggle in self-representation in any of these areas depending on individual variables. Tierney (1995) argues that irrelevant of the specific perspective on voice, writers need to consider the reader of the text they are producing (Hirvela and Belcher, 2001, p.88). Having this reference to the reader makes one think about the rhetorical situation one is in, which includes the writer, the reader and the text, again. This interplay in self-representation in writing, then, calls for a distinction between what the writer is doing and what they are being (Hirvela and Belcher, p. 89). In that sense, the voice the writer is using in their texts, is partly constructed by the reader (Matsuda and Tardy, 2008), making it an interpersonal process. Therefore, the influence of the written texts on the reader becomes a key factor in defining voice (Matsuda and Tardy, 2007) since 'self-portrayal' would change depending on who the writer is writing for, making the voice of the writer situational (Hirvela and Belcher, 2001, p.89).

As one appropriates their voice depending on the audience, they also consider how they

need to situate themselves within the text. Textual positioning becomes especially important in the use of academic voice since writers, especially emerging scholars, try to invest in the communication they are becoming a part of in their academic social community through their writing, they reveal certain kinds of linguistic behaviors while positioning themselves in 
different levels: within their field with fellow scholars, with their ideas and how they present them, and their textual communication. Their academic social identity, similar to other aspects of identity, is under the influence of power relations (Norton, 2000), and it creates 'sites of struggle' (Pavlenko \& Lantolf, 2000) as they try to situate themselves within a social discourse in the academia. They can either choose to 'participate' in interactions by conforming to the socially constructed roles or identities presented to them or expected of them in their disciplines, or they can take agency and display their identities in a way they desire to; making their 'subjectivity' a site of struggle as well (Norton, 2010). As they take agency in their choices, they create a discursive voice, signaling their identities as reflected in their language use, making their writing 'indexical' (Prior, 2001, p.62). As they gain experience and engage in various writing practices, they can learn to 'enact and exploit disciplinary genres for multiple agendas', and 'learn how their textual choices may be received and perceived by others.' (Matsuda and Tardy, 2007, p.246). As this set of knowledge and skills change, they can choose to 'conform or deviate from standards' in a way of their choosing (Matsuda and Tardy, 2007, p.246). Therefore, it is significant for students learning to write in academic voice to appreciate different ways of negotiating their chosen discursive practices, 'to break the rules properly, so to speak, so they can minimize the risk of being misunderstood' (Matsuda, 2001, p.51), and conform to the norms while at the same time creatively represent their selves in academic texts.

Since it can be highly difficult for students to find their own voice in academic writing (Grabe and Kaplan, 1996, p.373, in Hirvela and Belcher, 2001, p.88), it is essential to investigate how emerging scholars, graduate students, grapple with it, especially the ones with multilingual writing experiences. Looking at the voice representations of 6 international graduate students in their study, hence, Ivanic and Camps (2001) provided great insights into the identity negotiation 
of these individuals who were 'at an intersection between two positions in the academic community’ (p.28) being both a student and a researcher in different disciplines and trying to find their academic identity. They looked at the writing samples of these graduate students where they analyzed the linguistic choices they made at the lexical, syntactic, and rhetorical level, and concluded that each of these writers drew on their voice types based on the way they positioned themselves within their disciplines, taking into consideration the expectations and feedback of their professors reading their texts, and how they used other texts to shape their writings. The content of their writings revealed what they valued or believed in or their stance on an argument, as deducted from their lexical and syntactic choices; and how they used other scholars' work to support their arguments through paraphrasing or quoting, sometimes making it ambiguous to see who the voice belonged to; or taking clear ownership of their utterances depending on the power relations between them and the readers. In that sense, they made use of various discursive and non-discursive elements when they were negotiating their diverse identities either by simultaneous or heterogenous positioning.

Relying on intertextuality and interdiscursivity in academic writing as they create 'hybrid texts/utterances' (Fairclough, 1995 in Prior, 2001, p.65), thereby, creates texts that are also 'quite literally multi-voiced' (Prior, p. 68) because creating such texts are a way of 'reenvoicing' and 'dialogic' in nature (Prior, p.65). To investigate further how these texts are formed by multilingual individuals, Prior proposed that specific choices made by the writers are a result of the fact that 'there are no voiceless words' (Bakhtin, 1986, in Prior, 2001, p. 60). He argues that texts are simultaneously sites of both personalization and socialization, disapproving the longstanding dichotomy in between. 
As voice is achieved differently in different languages, a student who writes in their first language might have difficulty transferring their writerly selves in writing in English, as the discursive features in one may not exist in another (Matsuda 2001, p. 51). 'In order to construct their voice in their target language, then, L2 writers need to develop a personal repertoire of discursive features and strategies in the language' and in doing so, they should familiarize themselves with the norms and conventions of the discursive practices in the target language. To this end, they should learn how to shuttle between different demands of discourses in different languages in which they are writing. For non-native English speakers, it may pose a greater challenge as they are not just learning how to write in 'academese' (Hirvela and Belcher, 2001, p.86) but also, they are trying to master the language in doing so to meet their needs as multilingual writers. That is why, acquisition of academic voice and discursive identity in the target language or finding one's own way to represent oneself is an inevitable 'aspect of writing proficiency, possibly related to specialized genre knowledge, that can benefit from instruction as students develop their writing expertise as writing voice is directly related to 'overall effectiveness' (Matsuda and Tardy, 2008 p.102).

To respond to these needs, Matsuda (2001) defines voice in a broader sense by borrowing from Ivanic (1997) and Johnstone (1996) as 'the amalgative effect of the use of discursive and non-discursive features that language users choose, deliberately or otherwise, from socially available yet ever-changing repertoires' (p.40) and affirms that it is an essential part of identity (p.41) and disclaims the arguments that it has no effect on writing assessment (Matsuda and Tardy, 2008, p.104). As an activity, since voicing is a process rather than a product and is in constant change (Hirvela and Belcher, 2001), it is also an act of 'creating, changing, and understanding the internal and external identities that cast us as writers, within the confines of 
language, discourse, and culture' (Cummins, 1994, p.49 in Hirvela and Belcher, 2001, p.90-91). Therefore, Hirvela and Belcher propose that the notion of voice requires reconstruction to be used as a tool to create meaningful discussions on self-representations of identity in L2 writing, drawing on students' L1 and L2 experiences (p.88).

To this end, this study will build on the work of such scholars as Prior, and Hirvela and Belcher, as well as Matsuda, Tardy, and Ivanic and Camps in the sense of seeing writing, even academic writing often regarded as impersonal, as a means for self-representation through personalization of the text being produced while at the same time for socialization within the discourse communities- combining internal and external identities one possesses, especially those individuals who have experienced writing in different linguistic contexts and who have diverse linguistic resources.

In the next chapter, I describe the research strategy that I have used to study the identity and voice representation of multilingual writers producing texts in English across disciplines. Building on the conceptualizations and existing research in the field of second language writing as described in this chapter, I present a more detailed consideration of the methodology chosen for this particular study and the rationale behind the methods used to gather data and analyze them. 


\section{CHAPTER III: METHODOLOGY}

\section{Introduction}

In this chapter, I provide a detailed description of the methodological approaches I adopted to conduct my study of voice and identity representations of multilingual writers writing in their disciplines. Through the use of qualitative research framework, I mainly focus on three case studies whereby I have had individual interviews with my participants and conducted a textual analysis to cross-reference what themes emerged during the interviews with what kind of linguistic choices they made within their texts.

Drawing on the previous research on identity and voice issues in second language writing, the focus of this study is on the writing identities of three international graduate students while composing academic writing. In an attempt to understand their decision-making processes in writing in the languages at their disposal as well as the probable relationships between them, I have taken the following research questions as the basis for the research:

1. How do multilingual students negotiate different aspects of their identities in their academic writing practices?

2. What are some of the discursive acts they make use of in disciplinary writing as a way of self-representation?

In its simplistic terms, qualitative research is a method to gather data on a subject through non-numeric ways. Hatch (2002) states that definitions of qualitative research tend to vary as they can range from being too straightforward to highly descriptive or to more product-oriented ones. In Merriam's (1998) definition, qualitative research is interested in uncovering the meaning that people have constructed, '[....] that is, how they make sense of their world and the experiences they have in the world' (p.6). In that sense, it can demonstrate how every part of the 
whole phenomenon works together and how the meaning is negotiated through the researcher's perception, as well (Merriam, p.6). Among the characteristics of qualitative research, then, as Hatch (2002) lists, are the natural settings, participant perspectives, researcher as data gathering instrument, extended first-hand engagement, centrality of meaning, wholeness and complexity, subjectivity, emergent design, inductive data analysis, and reflexivity. These features of the qualitative research, in that sense, help us understand 'how individuals make sense of their everyday lives' and how we can understand what is happening in the lives of the people involved from their perspective as we get to spend extended amounts of time with the participants which leads to rich data to work with (Hatch, 2002, p.7-8).

Additionally, since qualitative research accepts that 'social settings are unique, dynamic, and complex' (Hatch, 2002, p.9), the study of the context in a systemic manner becomes crucial as inclusion of as much detail as possible about the subject(s) being studied creates a more complete picture for analysis. Hence, it is also natural to see the research trajectory change as the data collection continues. This feature of qualitative research is what makes it a 'hypothesisgenerating' one as the hypotheses are formed once all the data is collected (Seliger \& Shohamy, 1989, p. 120). As the product of qualitative research is 'richly descriptive' (Merriam, 1998, p.8), or 'non-experimental' (Seliger \& Shohamy, 1989, p.117), having an interpretive approach to the data gathered - as opposed to positivist and critical, which are the other two orientations to qualitative research in education according to Merriam- becomes inevitable as qualitative research is heuristic rather than deductive (Seliger \& Shohamy, 1989, p. 116) in its mode of analysis.

According to Seliger and Shohamy (1989), more and more researchers are leaning towards qualitative methods in second language research for reasons such as increasing 
awareness of the need for rigorous data and analysis as well as the uniquely insightful data elicited through natural settings as opposed to experimental settings which could bear 'controlled and artificial' data (p. 119). Lazaraton (1995) also states that qualitative research in the field of applied linguistics and second language studies is gaining more prominence, adding that such research has gained great 'visibility and credibility' in recent years (p.456). Similarly, Davis (1995) acknowledges the increase in the acceptance of qualitative research in education, and claims that 'both case studies and elicitation techniques' have been used to look into the mental strategies at play in acquiring a second language (p.428). Since 'applied linguistics is more than language teaching and learning', through qualitative research, we can have a better understanding of the 'complexities, difficulties, and discoveries' of the participants' languagerelated activities and learning processes (Duff, 2008, viii). Moreover, as the field of applied linguistics deal not only with language use but also 'the contexts and experiences of language use' (Croker, 2009, p.4), to examine what is at play among the individual language users, such qualitative research methods as narrative inquires, case study interviews, or linguistic ethnographies as well as multimodality are frequently used to gather exploratory data currently in the field of applied linguistics (Litosseliti, 2010). In this regard, Holliday (2015) also states that by use of qualitative research, applied linguists can expand their understandings on 'social and political issues connected with language and language education' (p.50).

For a deeper understanding of the wide range of issues surrounding language, then, among the many types of qualitative research that can also be considered as techniques to gather rich data, for qualitative interviews, Talmy and Richards (2011) state that they are ubiquitous in applied linguistics research and they provide ample data as they usually consist of open-ended questions that prompt the respondents to give extended information and their perspectives on the 
subject matter (in Hatch, 2002, p.23). Along with this type of primary data collection technique, though not very common in education (Hatch, p.25), an analysis of artifacts can also be conducted, where we can assemble 'indicators' of individual life (Schwartz \& Jacobs, 1979 in Hatch, p. 25). Thus, I have selected a qualitative approach for this research study and a case study technique to gather 'comprehensive, holistic, expansive and richly descriptive data' (Merriam, 1998, p.9) by using structured interviews for initial data collection.

\section{Case Study Research}

Case studies in second language studies can be described as approaches where the researcher tries to uncover and describe the performance or the development of the subject(s) (Seliger \& Shohamy, 1989, p. 125). Therefore, in this study, I embrace the case study technique to have a better understanding of the thought processes of multilingual writers producing academic texts in their disciplines as they represent their identities. Through these case studies, I have gathered thick descriptions of these multilingual writers' understanding of different identity aspects and the relationship between the different combinations of those aspects with how they compose texts, and especially their writer identities as emerging scholars in the academia and how it relates to the different and unique ways they represent themselves in written academic texts. Through a series of interviews focused on different aspects of writing as well as textual analyses of their academic writing samples, I have been able to gather in-detail qualitative data.

Hatch (2002) states that case studies are 'a special kind of qualitative work that investigates a contextualized contemporary phenomenon within specified boundaries' (p.30). Then, by studying the subject(s) at hand in depth and in a holistic manner, case studies ' [....] explore the details and meanings of experience and do not usually attempt to test a priori 
hypothesis. Instead the researcher attempts to identify important patterns and themes in the data.' ('Qualitative Research', 2019).

Since it is a part of the qualitative research, similar to the features of a qualitative methods, then, Gall, Borg, and Gall (1996) list the characteristics of case study research as follows: '(1) the study of phenomena by focusing on specific instances, that is cases; (2) an indepth study of each case; (3) the study of a phenomenon in its natural context; and (4) the study of the emic perspective of case study participants' (p.545).

In that sense, with careful analysis of the data gathered through case study, we are more interested in 'discovering or describing' the second language performance or development in its natural state/context (Seliger \& Shohamy, 1989, p.124). Through in depth analysis, then, case studies, including the one at hand, are to be descriptive and interpretive of the data gathered. In the field of TESOL, recently, too, the tendency to focus more on the issues of learner and teacher identities as well as development of various skills and language policies have become more prevalent ('Qualitative Research', 2019). In line with these foci, as Merriam summarizes, the emphasis in this research study is on '[...] process rather than outcomes, [....] context rather than a specific variable, [....] discovery rather than confirmation' (Merriam, 1998, p. 19).

\section{Case Studies of Graduate Writers: Textual Analysis of Writing in L2}

The type of case study I adopted in this research study includes ethnographic as well as text-based approaches to understanding the voice and identity issues that mature multilingual writers experience during their studies in the graduate school in the US, either for their master's or doctoral studies, having come from varying linguistic and educational backgrounds which have influenced how they view writing, especially in academic contexts. 
According to the Open Doors Report, the number of international graduate students in the US universities in the academic year of 2016-2017 is 382.953 (iie.org), and Olsen (1998) states that half of the theses and dissertations in the US are written by students for whom English is not the first language. Therefore, research on the academic writing processes of such multilingual graduate students is highly important in the sense that they provide first-hand data for second language writing studies. Hence, in this thesis, I draw on the work of scholars who studied the writing processes of graduate students for whom English is not the first language from a case study perspective, including Roz Ivanic and David Camps, Alan Hirvela and Diane Belcher, and Paul Kei Matsuda. For example, in their case study of three non-native graduate students, Hirvela and Belcher (2001) studied the 'coming back to voice' processes of these writers' who were struggling to find their way around academese in English and their identity-related experiences. In their case study, they specifically looked at voice as an analytical device (p.84) in the experiences of non-native speakers learning to write in the academic discourses they were in by using the narratives to focus on the unique experiences and struggles of these already proficient writers in other discourses in their other languages. Another example of a case study in the field of second language writing is seen in Ivanic and Camps (2001) who examined the writing samples of six Mexican graduate students in the British universities to analyze their selfrepresentation in writing. They investigated voice as a tool to culturally and historically locate the writers by looking at their linguistic choices in the texts they produced in the 'intersection between two positions in the academic community'; one being the student and the other the researcher (p.28). Through case study methodology, these researchers were able to better analyze the self-representations of the participants as each 'individual act of self-representation is unique' (Ivanic and Camps, p.7). Moreover, a more detailed look into the individual cases of these 
multilingual writers, 'especially with respect to self and identity, demonstrates that reports of voice-related experiences are multilayered and must be viewed from a variety of perspectives' (Hirvela and Belcher, p.86). Therefore, these personal accounts provide the unique experiences of each of these individuals writing in English as a second language and in academic contexts.

In addition to collecting data through interviews in case studies, Matsuda (2001) also analyzes the writing of a Japanese woman in a personal web diary to show that L2 writers have an individual repertoire of discursive features and they can use these resources in divergent ways to fit their needs and purposes. He presents certain excerpts in his article to exemplify the nonconforming usages in the varieties in Japanese and in English as a representation of the unique voice the individual has in composing texts. Prior (2001), with the aim of exploring an alternative understanding of voice and understanding writing as literate activity, conducts textbased interviews where the respondents examine their own texts with the interviewer. He uses these textual artifact-based interviews to uncover a range of rich thinking and textual practices that might not otherwise be visible. To this end, in the second round of interviews, I have also used text-based interviews as a think-aloud process with the participants regarding their choices in an academic text that they have completed recently to give them a chance to negotiate their thinking, writing, and meaning-making processes.

Such a textual approach to academic writing in varying disciplines is 'central to understanding the situatedness of academic writing and knowledge construction of multilingual writers' (Seloni, 2014, p. 82). Therefore, besides structured interviews, to better understand what goes into the decision-making processes of these multilingual writers while writing in English in their disciplines, I have also conducted a textual analysis of academic texts produced by the participants in the previous semester to the data collection period. Systemic Functional 
Linguistics has been chosen for the framework for the textual analysis of written texts collected in the second interview. Michael Halliday introduced this functional linguistics concept as a ' $[\ldots .$.$] descriptive and interpretive framework for viewing language as a strategies, meaning-$ making resource $[\ldots .$.$] showing how simultaneous strands of meanings (the ideational,$ interpersonal and textual metafunctions) are expressed in clause structures' (Eggins, 2004, p. 2). In this regard, Systemic Functional Linguistics deems language as a resource for negotiation and construction of our humanly experiences, and it shows how linguistic choices add to the system of how we realize ourselves in social situations, making it a 'principal resource for meaningmaking' (Fang, 2004, p. 336). Therefore, it is the language that allows us to make lexical and grammatical choices based on our individual needs and purposes in a given social context (Fang, p. 336), as we, at the same time, carry out tasks such as topic selection, organization of information, considering the roles of negotiation (Schleppegrell, 2004 in Fang, p.336). Therefore, as we create texts, in spoken or written form, we produce 'a rich, many-faceted phenomenon that means in many different ways' which 'could be explored from many different points of view (Halliday, 2013, p.3). When analyzing or interpreting texts, then, we also take into consideration the contexts in which they are produced, which are in themselves 'numerous and varied- educational, social, literary, political, legal, clinical and so on'(Halliday, p.4).

Similarly, in my case study of three international graduate students, I do the same in the sense that by looking at these multilingual writers' previous experiences and practices in writing, both in academic and non-academic contexts, I have collected data from their academic writing in English as a second or additional language to build on these scholars' work on identity and voice issues in writing, as Tardy (2009) proposes, along with more support from advisors, second language learners writing in the academia tend to use all sorts of textual and social 
resources available to them, by also tapping unto their previous knowledge of other genres they are already familiar with. By consciously or unconsciously making the transfer of skills and knowledge, these multilingual writers use a variety of resources linguistically or otherwise.

Consecutively, in line with gathering first-hand data from the writers themselves, I also urge them to negotiate their meaning-making processes and linguistic choices, as well as thematic, rhetorical, and organizational, by the use of text-based interview followed by a linguistic analysis of their written academic texts with the aim of (1) understanding the underlying reasons behind their choices in producing these texts in terms of how they represent and negotiate their identities, (2) interpreting the textual choices they made while doing so, and in the end suggesting some pedagogical approaches for instructors teaching such multilingual and multi-voiced individuals.

\section{My Study}

In order to better understand the underlying reasons for linguistic, thematic and organizational and rhetorical choices behind the academic writing processes of international graduate students, this study examines the writing processes of three multilingual graduate students across disciplines and therefore contributes to previous scholarship by specifically focusing on voice and identity representation in academic writing in English as an additional language.

\section{The Context}

This case study took place in the academic year of 2018-2019 in a Midwestern university, where the graduate students constituted the $48 \%$ of the international student population at the 
time of the study ('International Statistics', 2018). In the Fall of 2018, of 20,635 students enrolling in the university, 2.528 of them were graduate students and $25 \%$ of all the student population on campus were from traditionally underrepresented groups. (Jome, 2018). As of Spring 2018, the number of male graduate students were 823 while females were 1545 and nonbinary or not disclosed were 2 ('Enrollment Report', 2018). From the new enrollments, 145 were international students, mainly coming from India, Ghana, China, Bangladesh and South Korea, and only 31 were from Social Sciences while the majority were from Computer and Information Sciences and Business, Management, and Marketing departments ('International Statistics', 2018), and 787 of the graduate students in Spring 2018 were from College of Arts and Sciences ('Enrollment Report', 2018).

\section{Participants}

In total, three students from the College of Arts and Sciences agreed to participate in this study. One of the common denominators of the participants is that they were all, at the time of the study, graduate students in the Midwestern university where the data was collected. Additionally, English is not their first language but rather a second or additional language, which they have been exposed to for various reasons for long periods of time. Mostly they have learned English as a foreign language in school contexts, and they have also studied other languages throughout their education, and therefore, can all be considered multilingual. Below, I give a snapshot of each of the participants, focusing mostly on their background with languages.

\section{Orsi}

Orsi is a first-year MA student in Cultural Anthropology and she is from Hungary. She has been living in the US since she was six years old, having moved with her family after living 
in Israel for a very short amount of time after Hungary. She speaks Hungarian with her entire family and relatives, but she knows 'English better than Hungarian' (Orsi, $1^{\text {st }}$ Interview, January $\left.8^{\text {th }}, 2019\right)$ and frequently finds herself using literal translations from English to Hungarian. Although she does not remember any of it now, she has also learned how to speak Hebrew, and she also learned to speak English while talking to her stepdad who is Russian. During high school, she was also exposed to German, choosing to learn it due to its similarities to English.

\section{Murat}

Murat is an exchange MA student in History in the US but he is a PhD student back in his home country, Turkey. He got his BA degree in Turkey in Industrial Engineering and MA in History. At the time of the study, it had been only five months since he and his wife moved to US. His first language is Turkish, however, he also uses English, French and Arabic for academic purposes. He has been using English since $4^{\text {th }}$ grade when he started taking English classes in school, but mostly he has been using it for academic purposes since he started collegewhich is an English-medium university in Turkey. He considers himself proficient in all skills in English, but his French and Arabic are not that strong yet; he took French classes in college and got to the intermediate level, and even though reading and writing in French is not problematic for him, his listening skills are not that good. For Arabic, he started to take classes the year prior to study, thinking that he would use it in his studies and got to the level of intermediate. He does not speak it, but he can read and understand spoken Arabic fairly well. All his recent reading practices in French and Arabic are 'for fun' (Murat, $1^{\text {st }}$ Interview, January $9^{\text {th }}, 2019$ ) as all his academic research is conducted in English, but he reads newspapers in both Arabic and French. 


\section{Abigail}

Abigail is a first-year MA student in the Anthropology department. She is from China, and at the time of the study, she had been living in the US for four years. She has a BS degree in Finance from a Chinese university, where she actually received a dual degree with English, as the university she attended has an international studies focus. She moved to US to pursue an MS in Finance and upon completing it, she started her second degree, MA, in Anthropology in another Midwestern university. She mainly uses English for academic purposes, and Chinese to communicate with her family and friends at the moment.

The table below is an overview of the participants' linguistic and educational background. 
Table 1

Overview of Participants

\begin{tabular}{|c|c|c|c|c|c|}
\hline Name & $\begin{array}{l}1^{\text {st }} \\
\text { language }\end{array}$ & $\begin{array}{l}\text { Other } \\
\text { languages }\end{array}$ & $\begin{array}{l}\text { Current } \\
\text { education }\end{array}$ & $\begin{array}{l}\text { Educational } \\
\text { background }\end{array}$ & $\begin{array}{l}\text { Previous } \\
\text { writing } \\
\text { experience }\end{array}$ \\
\hline \multirow[t]{3}{*}{ Orsi } & \multirow[t]{3}{*}{ Hungarian } & \multirow[t]{3}{*}{$\begin{array}{l}\text { English, } \\
\text { German }\end{array}$} & \multirow{3}{*}{$\begin{array}{l}\text { MA, 1st year, } \\
\text { Cultural } \\
\text { Anthropology }\end{array}$} & Pre-school in Israel & Journaling \\
\hline & & & & $\begin{array}{l}\text { Schooled in the US } \\
\text { afterwards }\end{array}$ & $\begin{array}{l}\text { Online } \\
\text { platforms }\end{array}$ \\
\hline & & & & & $\begin{array}{l}\text { Creative } \\
\text { writing }\end{array}$ \\
\hline \multirow[t]{2}{*}{ Murat } & \multirow[t]{2}{*}{ Turkish } & \multirow[t]{2}{*}{$\begin{array}{l}\text { English, } \\
\text { French, } \\
\text { Arabic }\end{array}$} & \multirow{2}{*}{$\begin{array}{l}\text { MA, History, } \\
\text { (Exchange } \\
\text { student from } \\
\text { PhD) }\end{array}$} & $\begin{array}{l}\text { BA Industrial } \\
\text { Engineering, Turkey, } \\
\text { MA History, Turkey, }\end{array}$ & $\begin{array}{l}\text { Research } \\
\text { articles }\end{array}$ \\
\hline & & & & $\begin{array}{l}\text { PhD History in } \\
\text { Turkey } \\
\text { (All in the same } \\
\text { English-medium uni.) }\end{array}$ & $\begin{array}{l}\text { Online } \\
\text { platforms }\end{array}$ \\
\hline \multirow[t]{2}{*}{ Abigail } & \multirow[t]{2}{*}{ Chinese } & \multirow[t]{2}{*}{ English } & \multirow{2}{*}{$\begin{array}{l}\text { MA, 1st year, } \\
\text { Anthropology }\end{array}$} & BS Finance, China & Journaling \\
\hline & & & & MS Finance, US & $\begin{array}{l}\text { Online } \\
\text { platforms }\end{array}$ \\
\hline
\end{tabular}

\section{Data Sources}

The data has been derived from two major sources: (1) two sets of individual interviews with the participants after the initial data collection via e-mails for background information, and (2) textual analyses of academic writing samples collected from the participants. The first interview with the participants was the introduction to the research study and focused on general writing-related practices, academic writing experience and some discipline-related writing activities they do, while the second were more text-based where they responded to questions 
related to how they present themselves in academic writing through specific choices they make during the process. When the interviews were completed, the textual analysis with the use of Systemic Functional Linguistics (SFL) was conducted, giving more emphasis on the textual choices in the writing samples provided by the participants and compare them with what they shared ruing the interviews.

\section{Data Collection}

After obtaining IRB approval to conduct my study in the Fall of 2018, I contacted the graduate coordinators of the various programs on campus and asked them to forward the recruitment e-mail for the study. Through initial e-mail exchanges, I introduced the study in more detail to the volunteer students who contacted me directly, and with those ones who consented to being a part of it, we set up the first round of interviews, which extended from the end of December to the end of January. Before the initial face-to-face meetings, I sent them all a pre-interview survey (See Appendix A) to gather some initial demographic data that could help shape the first interview questions to a certain extent. By using the data gathered there, I added some extra questions to the original questions and also included some individually-tailored questions and commentary for their interviews. In the first round of interviews, all the participants signed the consent form stating that the data gathered throughout the study can be used for research purposes and that any disclosure of sensitive information would not take place. The first interviews started with additional questions that emerged as part of the pre-interview questionnaire, and then continued with structured questions about their backgrounds as writers, their writing practices in general in any language, the academic writing practices, and discipline 
related writing (See Appendix B). These first interviews lasted around 60 minutes each and were recorded to be transcribed selectively during data analysis.

The second round of interviews started right after the initial contact with the participants and continued until the first half of February, during which time, the academic texts recently produced by the participants were collected and the textual analysis procedure began. During the second interviews, the participants were asked questions related to identity and voice in writing in English as an additional language and they were asked questions regarding their agency and choice in academic writing, including but not limited to organization, topic, forming arguments, and positioning of the self. The second half of the interview focused more on the writing samples they brought and the questions were more specific to the individual choices made throughout the writing process of those texts (See Appendix C).

\section{Data Analysis}

Hatch (2002) describes data analysis as 'a systematic search for meaning' (p.148). To find meaning in the dataset, I conducted the analysis in a two-fold manner. The initial analysis was conducted by employing a thematic approach to the data gathered in the interviews, which was implemented through identifying patterns or themes in the dataset and organizing them in detailed categories (Braun \&Clarke, 2006; Fereday \& Muir-Cochrane 2006; Aronson, 1995).

Therefore, I have also looked at the overarching themes among the participants' narratives in conjunction with the academic texts collected from them and combined them into sub-themes for each participant. Once the dataset was established and important data categorized, I transcribed the interviews and focused on the critical moments and rich points, which are, as Agar (2006) describes, surprising and unexpected moments that 'signal a 
difference' between the native languaculture (LC1) and the target languageculture (LC2) and 'give direction to subsequent learning' (p.2). After I familiarized myself with the data gathered from each of the participants, I noted down the overall themes in their individual accounts separately. I specifically looked at how these multilingual writers positioned themselves in the texts they produced via metafunctions of their language use. In doing so, I identified certain initial codes for analysis based on the writer positionings in the academic discourse and academic texts at the ideational, interpersonal, and textual level.

Utilizing the tools provided by Systemic Functional Linguistics, the second part of the analysis consisted of close reading of linguistic markers such as the use of modal verbs, tenses, and personal pronouns to form, criticize or support arguments at the ideational level as well as topic selection and organization of information, and the use of specific adverbs to show certainty or to invite readers into the argumentation at the interpersonal level, showing rhetorical awareness. In combination with the interview transcripts, I more specifically looked at the written artifacts produced by the participants for their disciplinary courses in their first semesters in the master's or doctoral program and identified the textual markers for the way they represent their identity and voice in their respective academic disciplines.

As various ways of representing voice through writing helps us see 'how writers typically position themselves and their work in relation to other members of their groups' (Hyland, 2008, p.6), it is important to look at certain identity and voice markers in the texts produced for specific academic discourses by these writers. Through certain choices made at the lexical and grammatical as well as organizational, thematic and rhetorical level by the writers in composing academic texts in their disciplines, they create and represent their writerly voices in these texts. Hyland (2008) proposes a two-level academic interaction to analyze these key resources and 
discusses stance and engagement in detail. According to Hyland, stance is a 'writer's textual voice or community recognized personality, an attitudinal, writer-oriented function which concerns the ways writers present themselves and convey their judgments, opinions, and commitments' (p.7) through the use of hedges, boosters, attitude markers and self-mention (p.8). On the other hand, engagement refers to alignment, 'concerning the ways the writers rhetorically recognize the presence of their readers to actively pull them along with the argument, include them as discourse participants' (p.7), which is usually demonstrated with the acts of reader mention, directives, questions, knowledge reference, and asides (p.8). Therefore, taking Hyland's metadiscourse analysis techniques as the starting point for my analysis, I specifically focused on how these writers position themselves in their academic texts at the idea level through their stance and at the interpersonal level through their engagement with the reader or the audience with their uses of language in specific ways through their lexical, syntactical and rhetorical choices.

After careful reading and re-visiting the narratives as well as the texts and the sub-themes that emerged in the entire analysis, I have drawn descriptive and interpretive conclusions based on the common themes that arose across all participants via an inductive approach to explaining the qualitative data.

\section{Limitations of My Study}

Although this study offers insights into what kind of thought processes multilingual international graduate students go through in constructing their writing in academic spaces in an effort to self-represent, it has some limitations, especially in regards to the generalizability of the results. First off all, the methodology to gather data is case study research and thus relies more 
on the individuality of the practices portrayed and ideas shared by these participants only. Therefore, even though the study provides a clear understanding of what these particular participants need in the academic spaces they are in to exert their identities with multifaced and unique combinations, it does not and cannot speak to the general population of international multilingual graduate students who are diverse in their goals, who have different purposes of study and varying language experiences. However, that is already what I argue; that each student is unique as they have their unique antecedent experiences and the unique combinations of different identity aspects they possess, which is also shaped in part with the social factors- be it the people involved in the writing process - both the immediate and the imaginal readers- or the institutional academic spaces that allow variety to varying degrees. Therefore, these case studies, though not generalizable, aim to portray the diversity among students composing their ways in our classes.

In line with that, though, since I conducted the research with only the students of one Midwestern university per the requirement of the IRB approval obtained, and only the participants who responded to the recruitment call were chosen, two of them are from the same department and even from the same year of study. There has not been a variety in the disciplines to argue for a more general approach to analyzing writing practices across more disciplines.

Lastly, since my first language is also Turkish, I have conducted the interviews with Murat mostly in Turkish as well and I have translated our conversations myself. When there was some unclarity or other translation-related issues, I have contacted him later on as part of member checking afterwards to clarify, as well. However, it is important to acknowledge that there may have been some unintended misinterpretations. 
In the following chapter, I offer an in-depth description of the participants' experiences with academic writing in English, as it is influenced by their diverse background and experiences with languages and different ways of practicing writing as well as the way they conceptualize writing in their disciplines thus far. Emphasizing the unique representations of each participant in the way they present and position themselves in their academic discourses, I present the research findings by addressing the primary research questions of the study on a case by case basis, followed by a section where I discuss the common themes that have appeared through my overall analysis. 


\section{CHAPTER IV: RESEARCH FINDINGS}

\section{Introduction}

By providing detailed analyses of the four case studies, in this chapter, I present responses to the primary research questions: (1) How do multilingual students negotiate different aspects of their identities in their academic writing practices?, and (2) What are some of the discursive acts they make use of in writing as a way of self-representation?.

Firstly, I give a detailed account of each participant and the most frequent themes surrounding identity and voice in their writing, and then, I share the common themes across all participants as they emerged through the individual interviews and the textual analyses of the written academic texts of each participant.

Data analysis of interview accounts and written artefacts reveal that there are three major themes that emerged in response to the primary research questions:

1. These multilingual graduate students negotiate their disciplinary voices through predominantly linguistic and thematic choices in their academic writing practices.

2. These multilingual graduate students use multiple ways of argumentation in the academic texts they produce which are heavily influenced by their linguistic and cultural backgrounds as well as in and out-of-school interactions.

3. These multilingual graduate students integrate personal experiences and/or narrative style in their argumentation in their academic texts as a way to exert their changing identities as international graduate students and emerging scholars.

To begin, all of these multilingual graduate writers represent their identities in academic writing through discursive acts in two ways. Firstly, in terms of form, they make use of specific sentence structures such as forming sentences predominantly in declarative form in present 
simple tense. Additionally, their organizational preferences seem to center on primarily presenting opposing ideas in their paragraphs and then arguing for their ideas, which are also supported by other resources. Lastly, for lexical choices, what they all do is to include a vast number of adjectives and adverbs to show their attitudes in the subject matter.

In terms of the content related discursive features, what is prevalent in all three participants is their choice of topics in their papers. They all wanted to research and write about what is relevant to their academic and personal interests. In doing so, they all added their personal experiences as a form of supporting their arguments and/or used a narrative style. Finally, their argumentation strategies include having clear and direct statements considering the possible audience for their writing.

After presenting the unique backgrounds and experiences of each participant in using different languages for different purposes and presenting their narratives about how they have come to influence them as multilingual individuals and writers, I will focus more on their writing practices and writer identities as well as how they present their discoursal voice in academic writing in their disciplines. Lastly, I will present a more detailed account of the common themes for all of these participants in the way they negotiate their identities and self-represent themselves in written academic discourse.

\section{Orsi: 'The person in the essay is who I wish I could be in real life'.}

\section{Complex Identity Performances}

Orsi came to US when she was six years old with her family of a Hungarian mother and a Russian stepfather. Apart from a short period of kindergarten education both in Hungary and Israel, all her schooling took place in the US. Her entire family and relatives from her mother's 
side speak Hungarian and Orsi, as well, speaks to them in Hungarian as they do not use English as their primary language in the US. As a kid, since she was exposed to many languages, she used to confuse Hebrew, Russian, Hungarian and English words, not knowing from which language she would just throw words into the sentence, expecting people to understand what she was saying. However, as she grew older, she stated, she forgot the influence of the other languages and immersed herself in English, only to retain Hungarian, which she uses with her family members either in the summers when she goes to Hungary to visit them or talking to them over the phone. She told me in our first interview that she knows English better than Hungarian and that she finds it difficult to describe exactly what she is trying to say in Hungarian- often catching herself using literal translations both from English to Hungarian and from Hungarian to English (Orsi, $1^{\text {st }}$ interview, January $\left.8^{\text {th }}, 2019\right)$. One of the examples she gave me was that of the expression 'couch potato'; when she used it in a family gathering once, everyone laughed at this expression which did not match with the Hungarian equivalence, since in Hungarian, they have another expression for laziness that has nothing to do with couch or potato.

Orsi reported that she had several of similar occasions where her family members made fun of her or her use of language, making her feel stuck in between. When she was a kid, she would watch Disney movies 'because that was what everyone was talking about in school and I wanted to fit in' (Orsi, $1^{\text {st }}$ interview, January $\left.8^{\text {th }}, 2019\right)$, but she would be criticized for it at home with her parents telling her repeatedly that she was Hungarian and warning her never to forget that. In our interviews, Orsi stated that she does not entirely feel Hungarian but also not American, either, though she considers herself more of an American as she has lived here most of her life. She also shared with me how she 'faked' a Russian-Hungarian accent when talking to her stepfather in English ever since she was a little kid as they communicate only in English. She 
has told me she deliberately does that even though she has no clear foreign accent in English, and when I asked her why she thinks she does that, she states:

'It just doesn't feel right when talking to my stepdad like that! I feel like it's a habit, though maybe silly and awkward, especially when American friends are around, but my best guess is that learning to speak English was a cultural experience that looked completely different at home than in public school, especially because I grew up with negative perceptions of Americanness- whatever that means- at home, but positive perceptions of it in school. Speaking to my stepdad in an accent is like being a part of a completely different cultural and life experience that is separate from who I am as an American or Hungarian.'

She goes on with her story of how, when growing up, her parents were strict, emphasizing her Hungarian identity and imposing negative perceptions of Americanness, saying things like 'Only in America' or 'Stupid America', even though she acknowledges that 'There is no such thing as Americanness' during our interviews. They always wanted to maintain their foreignness at home, but at school, she told me, she wanted to feel American and have an American identity in order to fit in, and she liked her own perception of Americanness with watching Disney channels, playing with princesses and barbies. These were the American things for her but also for her parents as they told her with a judgmental manner: 'You're an American kid now!' or 'Oh, why can't you do your math homework? Because you're watching Disney channel because you're becoming American!' (Orsi, $1^{\text {st }}$ interview, January $\left.8^{\text {th }}, 2019\right)$. In this regard, her subjectivity has become 'a site of struggle' (Norton 2010, p.350). So, for Orsi, having that accent while talking to 
her stepdad, even as an adult now, is a way to connect with him and her Hungarian side, and it seems to me that while faking an accent in such an interaction with a dear family member, she is 'subverting' some parts of her identity, as Canagarajah (2004) puts it, to become more accepted from one part of her life.

She also stated that she feels like a different person speaking Hungarian as she retains some foreignness. 'Because as an American, my personality is different. I can be more flamboyant, outgoing. It's hard to explain' (Orsi, $1^{\text {st }}$ interview, January $\left.8^{\text {th }}, 2019\right)$. Also, she adds, 'It is a way of reconciling that judgement; no, I am not entirely American; I still retain this foreign identity, so judge me a little less, I guess'. Orsi's reflections on her own use of language differently with her family members is a clear demonstration of how we as individuals can be (un)motivated or (un)inhibited in certain social situations, signaling the power relations at play, which, according to Norton (2000), 'play a crucial role in social interactions between language learners and target language speakers' (p.12).

Such reflexive thinking on how she uses her languages and how she is betwixt different cultures goes beyond her immediate family, though. Last time she went to Hungary, she felt ridiculed by her stepfather's friends, who thought she did not understand or speak Hungarian and asked her stepfather to speak for her. Orsi reputedly mentioned that she felt really offended by it and long time after that she could speak to her stepfather about it; how she constantly feels like 'I have to prove that I understand Hungarian' (Orsi, $1^{\text {st }}$ interview, January $\left.8^{\text {th }}, 2019\right)$. Her extended family members also see her more American than Hungarian and some even keeps saying things like 'Remember that you are a Hungarian!' on family gatherings. So, she has been situated by others as belonging to one or the other cultural categories. Her culture is defined by national borders rather than the complexities and interconnectedness of her bicultural identity. Our 
identities and the unique combinations of different aspects we have are not that simple to explain and categorize, yet, we see here that she is exposed to such limiting definitions of who she is or who she should be. However, who she is and who we are is very much situational, contextual, and complex. In that sense, how Orsi participates in certain language acts reflects her choices in the way she represents her 'affiliation and belonging' to certain language, cultural, or social groups that she identifies herself most with (Pavlenko \& Lantoff, 2000 p.156). However, this does not mean that she is not in 'conflict with identities' among these different groups having completely opposite perceptions of her and her own perceptions of being (Nero, 2005, p.195).

In terms of knowing and using two languages to varying degrees and for different situations; Hungarian at home and with family members and English with friends and for pretty much everywhere else, she feels in between the two as she seems to think she does not know either language perfectly, but she also mentions English as her strongest language, and adding 'unfortunately' to her sentence because of her family perceptions.

'I am happy being Americanized- whatever that means, but I feel like there's a certain exoticized feeling of knowing a different language, which instantly makes you a cooler person in America. From that perspective, it would be better if I knew Hungarian a bit better, because it is only cool here. In Hungary, I am the person who doesn't know Hungarian that well because I am not fully part of that culture'. (Orsi, $1^{\text {st }}$ interview, January $\left.8^{\text {th }}, 2019\right)$

Having these two completely opposite perspectives on knowing the two languages to varying degrees and being able to use them for different purposes to communicate with different people, 
she still continues to feel in between. On the one hand, she enjoys having that 'exotic foreignness' among her friends. She recalls a time when she and her friends went to a grocery store where they came across some foreign products, including some Hungarian candy, and the fact that she recognized it and was able to read the labels made her feel cool among her friends; 'It felt really impressive!' she says. On a similar occasion, once she wrote an e-mail to her aunt upon her grandfather passing, and her aunt felt very proud of her because of her e-mail because she was able to write so well in Hungarian even though she does not do much writing in that language, which made her proud of herself, too. However, she also remembers using the Hungarian word for 'grapes' in a grocery list she wrote for her mother once but doing so with an incorrect spelling, after which her mother kept calling her on that repeatedly.

\section{'Humble Passive Activist' Writer Identity}

These complex performances and perceptions can also be observed in her academic experiences, which is also reflected in her writing, making her pause her thinking and writing at times. When I asked Orsi if she considered herself a good writer, in either language, she reported that in terms of her writing abilities, she considers herself an average writer in English. Since she rarely does writing in Hungarian, she did not elaborate on it much. Besides any writing she does for school purposes, she frequently uses Facebook to post her thoughts and keeps a personal journal. Any writing she does, though, is in English, unless she is writing e-mails or postcards to her family members, which does not happen frequently. She never mixes English and Hungarian while writing under any circumstance even if at times she has trouble remembering a certain word or a phrase in either language. 
Her personality adds a lot to her writer identity and how she writes in different situations. Orsi defines herself as 'introverted' and 'introspective', and as she said in one of the earlier interviews she is in her head a lot (Orsi $2^{\text {nd }}$ interview, January $\left.18^{\text {th }}, 2019\right)$. Orsi also stated that she enjoys being able to articulate her emotions in writing. While using spoken language to do so, though, she thinks about what she is going to say a lot before opening her mouth because she judges herself if she cannot describe it properly, and she does that even in her writing, as well, saying that 'I don't have a way with words as much as I should and that limits my writing, but that is not because English is my second language but mostly I am in my head a lot and I am an emotional person' (Orsi $2^{\text {nd }}$ interview, January $\left.18^{\text {th }}, 2019\right)$.

The way she describes herself with regards to writing also correlates with how she views a good writer and good academic writing, as well. She says: 'A good writer is able to articulate a feeling without being too pretentious' and a well-written academic writing '[....] goes to emotional theoretical side of it.' (Orsi $2^{\text {nd }}$ interview, January $\left.18^{\text {th }}, 2019\right)$. She seems to care about putting her ideas and feelings on paper and doing so properly and clearly, where sometimes her Hungarian knowledge comes into play:

'Sometimes I think of a word and stop and think- wait, that's Hungarian!- because that word would describe the emotion or thought perfectly. One word would be an entire phrase or even a sentence in English.' (Orsi $2^{\text {nd }}$ interview, January $18^{\text {th }}, 2019$ )

Making an unconscious connection between her emotional side and the Hungarian language, she admits not doing that in academic writing for the most part, yet she does think a lot about making emotions apparent in writing. More than once instance she talked about how she likes creative 
writing because it allows her to put her feelings on paper, unlike many of the other types of writing she does for academic purposes where she cannot do so that freely. Although she is familiar with ethnographies and narrative style within academic writing due to its increasing acceptability in her field, Anthropology, she says, she is still hesitant in integrating too much personal and emotional aspects to her writing for fear of being criticized for not being too professional.

\section{Writer Positionality}

'I see myself as a scholar or like an Anthropologist [pauses]. Well, I'm very modest, so I don't like calling myself an Anthropologist, even when I will have a master's degree, I won't be able to call myself that. I'm probably not going to because I don't know, I like to be humble. I'm not likely to say 'Oh, I know something. I'm this person' because then what if somebody reads it and says 'This is crap!'?' But I'm also somewhat of an activist: humble passive activist- which is completely oxymoron but [laughs]' (Orsi $2^{\text {nd }}$ interview, January $\left.18^{\text {th }}, 2019\right)$.

With this account, she seems quite insecure about her writing, which is probably because she is not ready to position herself as an anthropologist, so instead, the way I see it, she considers herself a novice writer in her discipline, because after all, she is 'a first year master's student' as she calls herself. Similarly, due to her personality traits, calling herself humble and introvert, she is cautious as not to sound too knowledgeable or confident, avoiding to embrace a highly scholarly identity. That is why she forms the oxymoron of 'humble passive activist'. When she talked more on that, though, what she meant by that became more clear. Orsi's research interests 
are related to social justice issues and she also talks a lot about them in her Facebook posts, as well. However, during in-person conversations, she tends to hold back her arguments in order not to sound too arrogant and also she is hesitant because she said her audience could be vicious, arguing for what they believe without recognizing any different perspective, and that scares her. So, on the one hand, she wants to make her activist identity more clear, and she sees her writing doing that better than her spoken interactions, and on the other hand, since she is not yet a 'complete scholar' but a student, she is aware of her possible lack of knowledge and therefore does not make sharp statements, hence calling herself 'passive'.

Throughout all our interviews and interactions, she constantly brings the worry she has about her readers. Being an introvert, she says she does not like sharing her writing; that she is 'afraid of fame and recognition' (Orsi, $1^{\text {st }}$ interview, January $\left.8^{\text {th }}, 2019\right)$. She does not want to publish any of her work in the future, either, saying that 'The thought of someone reading my work and not liking it really scares me.' (Orsi, $1^{\text {st }}$ interview, January $\left.8^{\text {th }}, 2019\right)$.

However, she also mentions how she writes with more confidence compared to spoken communication, referring to academic texts, adding that the academic environment she has at the moment is really supportive and potentially non-judgmental. She says both the professors or her peers would not '[...] disagree with me because I am writing my work. They will read my work and I will happily receive my feedback. So, it's not the same as being with friends who might have a different opinion. In those situations, I don't want to pull the college card, saying that I have a degree and I know the right answer, but in my mind 'I know this, I studied this, I am a scholar!', but I wouldn't say that because people are vicious and they ruthlessly defend their opinions.' (Orsi $2^{\text {nd }}$ interview, January $\left.18^{\text {th }}, 2019\right)$. Therefore, in a lot of her academic writings, she stated that she thinks of her audience as someone who might oppose to whatever she is 
arguing for and writes in a way to convince them by delivering it 'in a civil but authoritative way'.

'On paper, I am calm and I can eloquently express everything but if I meet somebody with opposite opinion, I'm instantly mad; I either shut down or have trouble expressing what I'm trying to say because I'm nervous because I'm trying not to yell at them [laughs]. The person in the essay is who I wish I could be in real life.' (Orsi $2^{\text {nd }}$ interview, January $\left.18^{\text {th }}, 2019\right)$.

With this account, it is clear to me that during face-to-face communication, regarding topics she is passionate about, it is hard for her to control her feelings, especially if she thinks she is knowledgeable about the topic and the person she is trying to converse with is not but they are stubborn about it. The emotions she feels so high in such moments seem to be preventing her from arguing for what she knows and believes to the fullest of her ability. Also, since she seems to fear being perceived as overly confident or even snobbish, especially regarding topics related to her research or studies- topics she is actually knowledgeable about, however, it is only in spoken communication because her writing suggests otherwise, showing that she has a different writer persona.

\section{Writing Sample: Ideational and Interpersonal Evidence}

At the time of the study, Orsi is a Cultural Anthropology student. She is already familiar with such school-related genres as ethnography, research papers, literature reviews, thesis proposals, argumentative papers and creative writing and narratives, and when asked what genres she had mostly written in in her discipline thus far, she counted ethnography reports and 
literature reviews as the most frequently used ones both in her field and in her experience as a student.

At the end of our first interview, I asked Orsi to bring a writing sample to our next meeting and that she could choose one that is important to her and that she spent considerable amount on it, weighing her decisions in the entire process. She immediately thought of her thesis proposal as she was really passionate about what she was writing about. That written artifact she provided for the study was produced the semester before during one of her courses, called Research Design, for which the book they followed was "Writing Your journal Article in 12 Weeks: A Guide to Academic Publishing Success" by Wendy Laura Belcher, chosen by the professor because, according to their professor, she stated, it had many valuable tools and it offered substantial advice on writing a publishable journal article. They spent half the semester to come up with a topic for their possible master's thesis for the following year, research the topic, write an abstract, and the other half with writing the introduction and literature review. The assignment asked them to write a literature review that could potentially become the literature review of their thesis. During the whole semester, they only worked on this isolated assignment, and each week, they submitted their writing to the professor for initial feedback and then they had peer-review sessions for each section to also get some peer-feedback. Orsi picked her topic based on her work experience the previous year when she worked for Americorps, during which time she tutored and mentored six year-olds. She wanted to base her arguments on her experience because she felt that the training she received was inadequate and did not prepare her and her team for some of the challenges. She stated that the experience there was difficult but inspiring for her: 'In Anthropology, they ask you what you really want to know or what you are curious about. For me, in my undergrad, I was exposed to Critical Race Theory, and I wanted to know more about 
people's experiences. I was curious why my team had such a hard time and see if it had to do with the big theme of America's racism.' (Orsi, $2^{\text {nd }}$ interview, January $\left.18^{\text {th }}, 2019\right)$. So, she wanted to interview people from diverse backgrounds and see how people view them, if white core members feel trained enough or how they feel about purposeful diversification. Therefore, her paper was titled 'Addressing the Race and Structural Inequity in Nonprofit and Community Development Work' where she discusses the racial identity and white bias in social service. When I asked her how she formed her arguments in her paper, she said:

'I had a lot of struggle there. Throughout my education, it's been tough. I wanted to be 'This is how it is' but especially because the way our country is, the more divided it becomes politically, it sounds really sketchy if you give a platform like for racist language and people overall don't have the same mindset. [....] And at least in academia, you're not supposed to put — at least that's the message that I've received from academia - you're not supposed to have your opinions, but I think in Anthropology it's a little bit different because you have like, for the lack of better words, a more creative license, so it's okay to use like first person. For example, there is a section here where I describe my AmeriCorps experience and how I felt that training was inadequate. So in those instances, I definitely take an opinionated stance when I say 'I observed that AmeriCorps didn't prepare us because these are the challenges my team faced' but even then I say 'This is how I see it' so it may not be how everybody sees it.' (Orsi $1^{\text {st }}$ interview, January $\left.8^{\text {th }}, 2019\right)$ 
Here is a her abstract from the final draft of her paper as it was submitted to the professor for a grade. As we can see there, as well, she uses an assertive voice when she uses present simple tense to present both facts and her own arguments and critiques. I noticed that she is firm with the way she argues. Her stance in the matter is very clear and she brings in where she stands on paper frequently. Even in her abstract, we can see how she puts herself into the writing:

In this paper, I discuss racial identity and white bias in social service. Racial identity plays into a complex power dynamic embedded in well-intended efforts, reinforcing the racial dynamics of charity, reform, and the definition of a community "in need." In any kind of social service work, there is frequent tension within the individual, between racially diverse co-workers, and with the surrounding community, and these tensions are negotiated in ways that do not account for bias and cultural differences. Drawing from my own experience serving in City Year-an AmeriCorps education nonprofit dedicated to bridging the education gap in "high need" areas around the country-I discuss key pieces of literature to guide my analysis of how white saviorism is embedded in social service efforts in the United States, specifically in AmeriCorps. I then analyze the literature and my experiences through Kimberly Huisman's critique of feminist ethnography and Julio Cammarota's analysis of the white savior. Drawing from the work of these two experts, I propose innovative and inclusive approaches to improving the current City Year model through participatory action research and Cammarota's concept of the "white ally."

She not only frequently uses self-mention, what Hyland (2008) categorizes as one of the ways to show presence as an authorial voice and stance in writing, using the first-person pronoun $I$ as well as possessive adjective $m y$ throughout to position herself in the discussion, she also 
demonstrates her attitude in the matter. The excerpt here shows that she uses present simple tense in sentences like '..there is frequent tension..' or '..white saviorism is embedded..' to assert her knowledgeable identity as a scholar with the use of such declarative sentences written with an authoritative tone and to discuss the matter with a firm stance. Her direct way of stating her ideas and arguments can also be observed in sentences such as the following:

Some members of SOS claimed that residing in the community is a way of understanding and claiming the right to represent neighborhoods of majority Black individuals. This is problematic because a white person choosing to live in a Black community is still a reflection of privilege and a sense of entitlement to represent people of color, along with the assumption that the individual would be welcomed in that community. (Emphasis mine)

However, race is often ignored in community development literature. (Emphasis mine)

While there is no direct evidence that City Year was ignorant of the importance of race at the time of its creation in the $90 \mathrm{~s}$, it does stand out as a clue that community development practitioners in the 90 s were not aware of the importance of education on issues of race. (Emphasis mine)

Diversity is arguably a strength of City Year as it ideally creates an environment where people of all backgrounds can come together, conversate, and fight for social 
justice. However, the reality is that this mindset can lead to disappointment when one is rejected by a member of the community, whether it is a student or teacher, based on one's racial category. (Emphasis mine)

These conversations, however, are necessary and beneficial because they allow for an awareness that one's way of doing things is not the default and may not necessarily be the "right way" of doing things. (Emphasis mine)

Orsi's attitude markers, which are the textual indications of 'the writer's affective, rather than epistemic, attitude to propositions, conveying surprise, agreement, importance, frustration, and so on, rather than commitment' (Hyland, 2008, p.10) show that she is highly opiniated in her writing. And they are also evident in the rest of the paper with her use of adjectives in phrases like 'the broken education system' or 'classes with outdated materials' or 'educators who are poorly trained and lack motivation' or to refer to a study she says 'a particularly interesting case study about the racial divide'. I believe her more clear opiniated stance as evidenced by such attitude markers come from the fact that she is a more confident person in writing. By using quotation marks for phrases like 'in need' or 'right way' she also gives her critical opinion and questions the factuality of such labels. In that sense, at the ideational level positioning, regarding how the writer represents the world (Ivanic and Camps, 2001, p.4), she firmly supports her stance and arguments by also acknowledging the opposite sides but refuting their arguments with clear and direct argumentation. She frequently uses her own experiences to provide supportthough she has received some comments from her professor that she might need to take some of them out, she has told me that she does not want to because they are all valid and relevant. Using 
her personal experiences with a narrative style, she also diverges from the expectations of the writing assignment and claims her writer identity in the space. In that sense, she creates her discoursal voice to defy the expectations of the genre she is writing in to integrate her own experiences in to support what she argues for.

At the interpersonal level of positioning, regarding 'the relative authoritativeness or tentativeness and in terms of the writer's relationship with the readers' (Ivanic and Camps, 2001, p.4), in the way she engages with the readers and brings them into the discourse, she presents herself as a reliable member of the academic community. She frequently uses possessive adjective 'our' to talk about either her own experiences or her team members while supporting her arguments. She also makes use of questions, though not frequently, to engage with the reader. For instance, in a section titled as 'Bias in Government Policies', she starts with the question to create a dialogical involvement with the readers: 'Why is there a need for nonprofit organization such as City Year?' and then goes on explaining the need. The abovementioned reader or audience awareness that influences the way she presents her arguments with confidence in writing also comes into play here. By creating this dialogical tone, she tries to argue against a possible disagreement, even from the beginning. Then, she supports her arguments with other sources, by quoting other scholars' work throughout her paper. Her use of intertextuality is mainly through quotes, rather than paraphrasing, because as she indicates in one of our interviews ' $[\ldots .$.$] sometimes what others write just summarizes everything so perfectly that no$ matter how I paraphrase it, it's not going to sound good.' (Orsi $2^{\text {nd }}$ interview, January $18^{\text {th }}$, 2019). Considering she does not want any disagreement or confrontation to her ideas, coming off with such firm stance puts her in a position where she can defend her opinions more easily. As part of her identity as an introverted person as she calls herself, she can make claims and form 
arguments better in writing and for an audience who will not likely to oppose her, clearly demonstrating her rhetorical awareness in her academic discourse.

In that sense, the way she describes herself as 'humble passive activist' and admitting how she aspires to be the person she represents herself on paper shows that she can stand up for herself and what she believes as right, especially if she is 'passionate' about it- something she mentions while talking about different aspects of her identity. She continues to describe herself as:

'Let's see. I am a white female. Hungarian-American. I definitely see myself as an American person. [....] Also being at this age and living in this political climate, being young and passionate about what's going on around us, I can say that all these factors make me feel like I am a more American, Americanized person because when I speak Hungarian, it's always with family and I avoid talking about politics with them.' (Orsi $2^{\text {nd }}$ interview, January $\left.18^{\text {th }}, 2019\right)$.

That is also why she says her voice in writing is English, as well. Additionally, the topic she chose to research and write about for her thesis- something she calls 'a buzzing topic these days in our country' (Orsi $2^{\text {nd }}$ interview, January $\left.18^{\text {th }}, 2019\right)$, the way she forms her arguments and presents her stance so clearly throughout her paper with firm and sharp sentence structures and specific word choices demonstrates that aspect of her identity as a passionate white Americanized female. 


\section{Murat: 'I am half-professional, half-storyteller'}

\section{Moving Between Languages}

Murat's experience is a little different from Orsi in the sense that he came to US five months prior to his participation in the study with his wife as an exchange student from Turkey, where he was a PhD student in the department of History. He got his BA and MA degrees from the same English-medium university there, though changing his major from Industrial Engineering from his BA to History in his MA. He started learning English in $4^{\text {th }}$ grade, as a subject course, but it was not until he started university that he actually immersed himself in the language. Since he has used English for academic purposes since then, he can efficiently use it in any academic discourse he is a part of. He has also studied French for academic purposes, and Arabic for a short period of time, but his strongest language is Turkish as it is his first language and he has spent most of his life in Turkey. He mostly produces research-based articles and sometimes conference papers in his field of study, and they are always in English, but for nonacademic genres, such as the ones he frequently uses (Twitter or Reddit), he reads and writes in both languages depending on the content, the specific online platforms, and genres.

\section{Linguistically Aware Writer Identity}

Having studied the Turkish language throughout his education in Turkey and even teaching Turkish as a teaching assistant in his university, too, Murat seems to have a very good understanding of how this language works and can use his lexical and grammatical knowledge of Turkish and his rhetorical awareness in general to his advantage while using English. He has published both back his home country four times and also once in an international journal as well as another one produced in collaboration with one of his current professors. All his publications 
have been in English, and he mentions that he has never written an academic paper in Turkish, even in Turkey or even about the topics covering Turkey and Turkish government. He adds 'unfortunately' to his sentence when he mentions this, indicating his desire to produce texts in his mother tongue.

In our first interview, when we were talking about the similarities and differences in writing academic papers in Turkish and English, I asked him if he ever attempted to write in Turkish or if he thinks he can after all these years of writing and publishing in English, he said: 'Compared to English, I'd write more easily, but I haven't ever tried. I want to write, speak, and teach in Turkish, but..' he stops, signaling the importance of English in the academic world, its dominance over the world and the capital value it has over other languages as well as its sociocultural and sociopolitical implications as a world language, signaling the effects of linguistic imperialism (Phillipson, 1992; Pennycook, 1994; Canagarajah, 1999; 2002) and the unlikelihood of it being removed from the social, cultural, economic and political contexts where it is widely used.

Lexical awareness that Murat brings to his new discourse community is reflected in the way he describes his writing process in English. When he writes directly in English, he considers his writing to be simplistic because of his word choices, therefore, sometimes he writes in Turkish and then translates what he has written into English to have a more 'elaborate' description, adding that the 'flowery' nature of Turkish allows him to create better texts, similar to Seloni's study of thesis writing process of a Columbian art historian student who navigated through academic writing with multiple modalities and languages to construct knowledge. 
'For example, if I directly write in English, I say 'The table is brown', but if I first think in Turkish and then translate that into English, I can come up with something like 'The color of the table is walnut brown' etc.' (Murat, $1^{\text {st }}$ interview, January $9^{\text {th }}$, 2019).

Murat also mentioned that he feels limited in his vocabulary while using English, especially with idioms and any usage with abstract meanings. As he indicated in his interviews, he finds it hard to understand the underlying meaning of some idioms or sometimes difficult to express them in the 'correct' form. He gives the example of 'raining cats and dogs', which he says can be expressed with another idiomatic expression in Turkish, completely different from the English expression, so he may not at times remember how to say it but explains it with other words during a conversation. In this sense, he bears some similarities to Orsi, for whom such idiomatic expressions at times have been problematic when conversing in Hungarian with family members. However, Murat emphasizes that such instances are not a big issue in writing as he can get help, from online dictionaries and other sources. As for Orsi, it seems to me that depending on the situation she finds herself in, she either explains herself or lets it pass without putting so much emphasis on it.

Since Murat also reads a lot of Turkish academic sources in his research, he is able to compare the language use between the two languages. He says the differences usually depend on the author of the text: 
'Generally if the writer is Turkish, they use a good language, but in English, if the writer is a native English speaker or not is mostly detectable; if it is their mother tongue they could use a heavy language- harder to understand. But let's say a Polish man, very good researcher but probably not that good with English, I look and say 'Looks like I wrote this'. (Murat, $1^{\text {st }}$ interview, January $\left.9^{\text {th }}, 2019\right)$.

When I ask what he means by heavy language and what gives him that impression, he emphasizes the use of words: 'An English speaking person has those GRE and TOEFL words, but the other person uses simpler words.' (Murat, $1^{\text {st }}$ interview, January $9^{\text {th }}, 2019$ ). He talks about the writer's identity and how he can detect if the writer is a second language user of English, based on his own awareness of his English use. He described to me his own use of English in writing and the way he makes use of language in his academic papers, saying that his professors would be able to identify him as the writer of the texts through his vocabulary use, for instance, which would show his area of study [the terminology he frequently uses] and his second language user identity [using a more simplistic voice]. Therefore, by looking at a written text produced by another second language user, he told me that he was able to guess the writer's identity through the linguistic clues embedded in the text, either by use of certain lexical items or basic grammatical structures.

As for Murat's grammatical awareness, we can see it shows primarily in the way he describes what he thinks of 'terrible language' which bothers him while reading or writing. He indicated in the initial stage of our first interview that terrible language use was one of his least favorite aspects about written language and that he cared about 'correct' use of a language, 
especially in Turkish, and he told me that he was easily disturbed by incorrect use of the Turkish '-de, -da', which means 'too' or 'either' and which is spelled separate from the preceding word, as opposed to locative case marker which has the same spelling but that attaches to the preceding noun in Turkish. He is also disturbed by any capitalization error in a text in Turkish.

Although Murat says he cannot easily detect the specific forms and structures in texts in English, probably because he does not pay specific attention to them, he is aware of the grammatical moves he makes in his own writing. He also adds that in any type of writing, '[...] grammar is the least important part because it can easily be corrected, either with online help, like websites like Grammarly, or by asking someone else to proofread it for you.' (Murat, $2^{\text {nd }}$ interview, January $\left.17^{\text {th }}, 2019\right)$. However, in both of the interviews, he talked a lot about how he is challenged by the use of tenses in English, which emphasizes the fact that academic disciplines often shape what we pay attention to in writing.

'When I use past tense, sometimes I say 'Wait, This is too past'. Actually, in my research studies, I want to use the structures like 'görüşüyorlardı [They were meeting/ They had been meeting], görüşmüşlerdi [They had met], oturmuşlardı [They had sat]' ${ }^{1}$ etc. but to translate these into English and to give the same meaning is really hard. [....] It doesn't totally work if I use simple past tense, especially when the actual time of the event is not definite. It gets really complicated, too. Probably the reader has a hard time understanding what I am trying to say.' (Murat, $1^{\text {st }}$ interview, January $\left.9^{\text {th }}, 2019\right)$.

\footnotetext{
${ }^{1}$ Since I conducted the research with Murat both in English and in Turkish, I translated this part myself.
} 
When I translated the Turkish examples he gave, I also had trouble choosing which tense to use, firstly because there was no context to give extra information about the usage, but also, the lack of perfect aspect in Turkish makes it difficult to give the same meaning in English, just as Murat mentions: 'I want to say 'This much time has passed since then or the effects of it still continue [.... '. Considering how important it is to use the time phrases and tenses in the field of History, his concerns about being accurate about how he delivers the events are quite valid at this point.

'My advisor [in Bilkent University] tells me to use either present tense or pastnothing in between, but it doesn't feel sufficient to me because he is also American. Maybe for him it is sufficient, but for what I'm trying to say [it's not]. [.... Maybe it can be solved with a person who speaks both languages as their mother tongue, who is sufficient in both grammars should look and say 'Yes, you're doing this mistake here' etc.' (Murat, $1^{\text {st }}$ interview, January $9^{\text {th }}, 2019$ ).

Murat seems to be prioritize his use of grammar in written communication. Another grammatical structure he kept emphasizing is the use of passives in academic texts such as research articles. 'Since I am not writing a memoir, I do use passive structures most of the time, and I refrain from using $I$ ' he says in our second interview when I ask him what kinds of choices he makes in forming sentences. Even when forming arguments, he says he starts his sentences like 'It can be said that or it can be supported that..' (Murat, $2^{\text {nd }}$ interview, January $17^{\text {th }}, 2019$ ). Later on he also adds that his use of passive structures in his writing is another factor that would help his professors identify his writing among others. He also seems to equate active voice, especially the use of personal pronouns, with memoir-like personal writings only, as opposed to 
academic texts which have a less personal emphasis to delivery of information, revealing his perceptions of genre conventions surrounding what is and is not an academic text and how they should be written.

As an addition to that, his use of long sentences also signals his writer identity. When we talked about his writing sample, the book review he wrote for a class previous semester, he said that his professor asked him to shorten his sentences to increase clarity, a comment I personally also frequently get from my professors about packing too much information into one sentence. That is when he said:

'Some of my sentences are too long. I think that is because in Turkish long sentences are considered good. If you say 'Ali went to school', they [the readers] can say 'So what?', but if you say 'Ali was going to school through the park in a sunny day' etc. it feels more important. But I think in American English, there is no need for these. The professors want shorter sentences and as long as they are clear, it is good. [....] It is bad if we cannot. Even in Turkish, it is difficult to have long sentences without having ambiguity.' (Murat, $2^{\text {nd }}$ interview, January $17^{\text {th }}, 2019$ )

With this account, he is bringing with him his assumptions about reader expectations, especially of his American historian community and revealing his awareness of the differences between the two rhetorics; how Turkish rhetorics might be working differently from that of English, creating different expectations (Robertson, 2010). However, it is also important to note here that his concerns about adding details and making his sentences more elaborate while describing a historical event could be common to other historians, whether they are native speakers of English 
or speakers of other languages, who care about the readability of their writing and address these concerns through certain lexical moves in their writing. I also know from my own experiences that writing long and elaborate sentences in Turkish is highly appreciated and valued, especially in literary genres, while thinking with that mindset and writing in English can result in unclear sentences. Therefore, sometimes it is hard to make the switch from one to the other in writing and keeping in mind the audience and the expectations they bring into reading our texts. In Murat's case, he seems to think that in American English, simple but clear sentences are expected of him and even though he may fall back into thinking in the Turkish mindset, he is often reminded of the change in the structures by his professors.

This rhetorical awareness and the critical analysis of his own writing, or academic writing in general both in Turkish and in English, helps Murat in his decisions in writing, and not only at the sentence level but also at the organizational level. He says he frequently uses signposting to help readers:

'I pay attention to starting, for instance, I start with 'firstly, secondly' and finish with 'eventually, to sum up, lastly' or if I am repeating one thing, I say 'too' or 'as well' at the end. $[\ldots .$.$] I believe these make me more understandable. Also, this is the way we$ were taught. Even in TOEFL samples, they say you can write better, but you don't have to; just use these and you can still get points. [.... I mean these make it more structural; more strict rules that you need to apply, so I try to use those in my writing, as well.' (Murat, $2^{\text {nd }}$ interview, January $17^{\text {th }}, 2019$ ). 
His reflection on his educational background, the way he was taught, reminds me of my own experience in learning to write in English, and after a while, my own teaching of TOEFL skills courses. I was also given the impression that these signaling words would give the reader a better understanding of your organization of ideas and would make the flow of ideas more clear. That is why I, too, encouraged my Turkish speaking students to use such linking devices when organizing their writing in English, which also boosted their confidence because seeing those couple of words on paper helps them see that they can still write, and even if it's not very long and elaborate yet, it gives them a starting point.

Since he predominantly writes academically in English, Murat mentions that the influence of his Turkish rhetoric is the least apparent in his organization. Even though he makes use of Turkish in the brainstorming or outlining stage in his mind and translates his thoughts into English, he takes notes, paraphrases, and starts writing directly in English: 'I think about the structure of the whole text in English because it will be in English.' (Murat, $1^{\text {st }}$ interview, January $\left.9^{\text {th }}, 2019\right)$.

\section{Writer-Researcher Positionality}

Murat considers himself a good writer in Turkish in general, and adds the factors contributing to this as 'grammar, content, originality, and cohesion' (Murat, $1^{\text {st }}$ interview, January $\left.9^{\text {th }}, 2019\right)$. On the other hand, in English, he says he needs to try harder to be as good. 'I need to think a lot and review a lot' he says. 'If I write without good effort, it is really bad in the end, and for good reason because it's not my mother tongue' (Murat, $1^{\text {st }}$ interview, January $9^{\text {th }}$, 2019). When describing what makes a writer good, he does not differentiate between any languages and says 'It is common for all; cohesion, content, maybe the least important is 
grammar but it's there still. If you want your writing to be read, it needs to be connected well; it should be coherent and it should have cohesion.' (Murat, $1^{\text {st }}$ interview, January $\left.9^{\text {th }}, 2019\right)$. Murat does not seem to differentiate among different text types and genres when it comes to good writing. As a second language writer, for him, the successful use of discourse markers separates a well-written text from a poorly-written one. The similar features arise when he talks about a well-written academic writing:

'It should be able to attract readers. What attracts me personally is fluency. Yes research is good and important but if you want to be a read historian, ${ }^{2}$ you have to pay attention to what we call good writing with coherence and cohesion. [....] It's not necessarily about using a simple language but more about giving contexts and details about events.' (Murat, $2^{\text {nd }}$ interview, January $17^{\text {th }}, 2019$ )

Taking into account the readability of his work, Murat makes a good point in identifying what he values more in his own writing, as well, also signaling his own writer identity. Whenever we talked about attracting readers, he implied using a narrative style, as part of creating a narrative historical account using story-based form.

'When I write, I write more in the narrative style especially if I want to be published. It's like there's a historical event but I'm trying to emphasize the events surrounding the storyline. It's called narrative history and it's an accepted style in my field.' (Murat, $1^{\text {st }}$ interview, January $9^{\text {th }}, 2019$ )

\footnotetext{
${ }^{2}$ Translation mine. He tries to say 'a historian whose work is read by others'.
} 
In our second interview, I asked him how he represented his writer identity with the textual choices he regularly made in his writing in English. How he described his identity as a writer is in conjunction with narrative style and how he makes his writing his by representing himself through this style. He said:

'I try to be half-professional, half storyteller when I write. I don't want to say 'This is what it is.' or 'This is what should happen.' I believe such sentences should be included and I do that in some places, but I should also tell a story so that it can keep the reader because by only theorizing something, it's hard to keep the audience engaged. [....] If I want to write a book in the future, too, to tell something, I think I'd still do the same thing. So, it's like investment in the future; if you want to be read, this is the way: a balance in narrative. [....] I mean it's like trying to write what you enjoy reading.' (Murat, $2^{\text {nd }}$ interview, January $17^{\text {th }}, 2019$ ).

Bringing what he enjoys reading himself and his reader audience again into the picture, Murat seems to take into account how his work and his writing is going to be perceived in the future, as well. By investing in his future as a recognized or valued writer of history, he is establishing and solidifying his writer identity through his stylistic choices in the present. To be a 'read historian', having a balanced delivery of narration and factual information seems to be a must to him. And as mentioned earlier, such concerns about readability of his work and addressing it with use of details, elaborate language and narrative style could be common among other scholars or graduate students in the field of history. 
Another aspect of writing in his discipline that Murat has emphasized throughout our conversations is thorough research and integration of good research in academic writing. Being able to do good research, finding relevant and reliable sources, mostly from primary sources, and integrating them into his argumentation is what he considers a strength of his, supporting this claim with what his professors usually comment on on his papers, saying that the feedback he usually gets is ' $80 \%$ about understandability and $20 \%$ research-based' (Murat, $1^{\text {st }}$ interview, January $\left.9^{\text {th }}, 2019\right)$. His strong views on research is also reflected on his choice of readings in his field. He says:

'Even though I haven't found my historian identity yet, I agree with both [pure factual presentation of historical events and use of narrative style], and I enjoy reading both, but as long as it's a good study, good research. The only thing I don't like is bad research, which looks at only one source or gives only one side of the issue.' (Murat, $1^{\text {st }}$ interview, January $9^{\text {th }}, 2019$ )

To strengthen one's skills to be a good historian, then, he values record keeping and good note-taking, from efficient sources sufficiently as these would lead to comprehensibility of the research through a good synthesis and evaluation. However, his ideas on research is not limited to only content research. He also mentions he does genre research frequently for his writing along with topical research. He says he looks at other articles written in similar topics first before starting to write his and tries to conceptualize his own the same way as the other people, changing it according to his focus in the arguments made (Murat, $2^{\text {nd }}$ interview, January $17^{\text {th }}$, 2019). He also gives the example of what he is doing these days in that he is looking at theses 
written in the department of History in the US university he has come as an exchange student to see what kind of topics have been covered or what kind of texts professors have looked at so far as he is thinking of writing a thesis the following year for this audience and in this academic discourse.

\section{Writing Sample: Ideational and Interpersonal Evidence}

The written artefact Murat chose to bring for this study was a book review he had written two months prior to the study for the course called Philosophy of History and Historiography, during which they were reading a book each week and writing a review for it. The assignment asked them to write a 3-4 page review essay, relatively short, where they were to focus on major themes, questions, and problems posed by the week's readings- not on any lesser details or minor aspects. The professor also told them in the guidelines to briefly summarize the theories and arguments put forward by the authors, and then analyze their arguments by comparing and contrasting if applicable, and if possible, they were to also put the theories in historiographical context, i.e, explain how the theories shaped the historiographical discipline (Murat, personal communication, February 25, 2019).

The review he brought was the sixth review he had written in that course and 'the strongest, most effectively written yet' according to his professor, and it was the review of the book 'The Age of Capital' by Eric Hobsbawn. Though he acknowledges that it is not entirely like a book review we could find in a journal, Murat claims that it is highly evaluative and he has written a highly critical evaluation of the ideas presented in the book, in a very subjective manner, based on the parts that did not speak to him and the parts that made him think (Murat, $2^{\text {nd }}$ interview, January $\left.17^{\text {th }}, 2019\right)$. 
At the ideational level of analysis, the way Murat positions himself with regards to how he 'represents the world' (Ivanic and Camps, 2001, p.4), I have noticed that his stance in his argumentation, in academic writing in general and in the book review specifically, is quite clear. He makes his side of an argument apparent through the way he composes his text. For instance, unlike what he has expressed in the interviews, he makes a conscious choice of using mostly present simple tense in writing the review and rarely uses passive voice. The only sentences he used passive structure were as follows '[...] the arguments are presented clearly and modestly $[\ldots .$.$] ', '[...] it is underlined that the revolutionary process differs [\ldots .$.$] ' and ' [\ldots .$.$] it is also$ explained that the revolutionaries throughout Europe fell from favor [....]', which are, as can be seen, mostly to start a sentence and to avoid repetition in the sentence structure. Additionally, even though he said that the book review was subjective and evaluative, it was interesting that he has not used any self-mention to create arguments or put forward his ideas. Instead, he relied on his lexical knowledge to present his side in his argumentation or criticism of the either the author himself or the ideas presented in the book.

'If you don't like something, you should [criticize it], but explain why because academic context is an appropriate place for it. You can't do it in many places; in a café, you can continue like 'A-huh' but in academia is such a place. If you don't agree with something, you should be able to say it and the opposite side should understand it. In this writing piece, for instance, I criticized a historian's book, who my professor loves, and he gave me 9.5 out of 10- the highest I got in that course thus far. He had talked about how great that person was whole class that week, and 
when submitting the paper, I kept asking myself if I should not give, but in the end I did and it was fine.' (Murat, $2^{\text {nd }}$ interview, January $17^{\text {th }}, 2019$ )

He says he did that because he thought the book was biased for a history book. He thinks the author's ideology should be reflected to a certain extent but also the author should present the different sides of the event or argument at hand. In that sense, his stance on how ideas should be presented by including multiple perspectives is similar to Orsi, who also stated that in any writing including opinions or ideologies, it is important to include different sides of the issue at hand to be fair to those readers who might have opposing ideas to what the writer is arguing for. Therefore, in his review, too, he wrote about his opinion on that clearly. He also used a small number of hedging- expressions of hesitation and likelihood (Hyland, 1998), and they are all in the same paragraph, towards the end, where he talks about his views on the book in general, considering the targeted audience of the book and the writing style of the author. For instance, he starts the paragraph with 'Finally, it would be fair to say that this book is not an absolute academic book suitable for general readers.' And 'Hobsbawn seems taking caring of the details[....]', but other than these two instances, he does not make similar moves in presenting his opinion.

His criticism or evaluation of the book, on the other hand, is represented through his choice of words that carry attitudinal values; attitude markers, mostly given with extensive use of adjectives and adverbs as evident in phrases such as 'coherent and encompassing narrative, unrealistic expectation, lacking an objective tone, or enlightening interpretation' as well as '[....] thoroughly depicts, uses sources sufficiently and narrates the age impressively, tremendously fertile source'. 
When we look at the metafunctions at the interpersonal level, that is writer's relationship with the readers, we can see that, as also mentioned earlier, he cares a lot about the readability of a text and thinks about the targeted audience of his writing during the writing process. To this end, he says he pays attention to coherence and cohesion within the content delivery, and thinks carefully about his grammatical and lexical choices with concerns dealing with understandability. The conscious decisions he makes in his language use often seem to result in the writing style he adopts with the narrative tone. In his book review, too, we can observe a conversational style where he integrates questions to engage readers. The following excerpts from his book review indicates his attempts to engage the reader in a way that makes his writing interactional:

If these changes were profound and influential in shaping the dynamics of the era, why are they considered as failures?

Yes, the Russian Revolution occurred in 1917. However, what if the allies could send the aid that the Russian Empire needed during the World War I? Would there be a revolution?

With the use of such reader engagement techniques, Murat shows his voice in writing through interactional linguistic acts. His efforts to keep the reader active also demonstrates his rhetorical awareness of the audience. For this writing sample, he takes his professor as the primary audience, but still keeps his usual writing style that he embraces in his other academic writings. And unlike Orsi, he seems less concerned with the feedback he is going to get from the 
professors in terms of the ideas he presents, and upon looking at the written feedback on his paper, I can also confirm that the feedback he usually gets is on the technical level such as some grammatical mistakes regarding plurals or subject-verb agreement or certain punctuation marks. To this end, he positions himself in the discourse more on the ideational level through his stance in the subject matter and through his identity aspects, which he describes as:

'As a male coming from Turkey, an academician candidate, [....] I believe that I think we are writing who we are ${ }^{3}$, however we are perceiving it, [which are] shaped by the time periods we are in. So, the time period and the dominant identity in that time period is reflected on our writing. [....] Some cultural perspectives coming from Turkey, too.' (Murat, $2^{\text {nd }}$ interview, January $17^{\text {th }}, 2019$ )

The cultural perspectives he mentions there include his remarks on Turkish language and writing in a context where the Turkish speaking community might shape the way he presents himself in writing, as well- or any other cultural context for that matter. When we were talking about using criticism in academic contexts and in academic writing, he mentioned how he would change his language use if he was writing in Turkish or if he was criticizing a Turkish professor's work. He says it's about 'social hierarchy' and that '[ $[. .$. whoever they are, you have to respect the elderly or senior people [in the field].' (Murat, $2^{\text {nd }}$ interview, January $\left.17^{\text {th }}, 2019\right)$. That is why he thinks writing in English in an English speaking context is easier for him. In addition to this, he also gives another example as to

\footnotetext{
${ }^{3}$ When I asked him what he actually mean by this sentence afterwards during data analysis, he added that 'Our writing and our style reveals our characters- that's why I said we write who we are.' (Murat, personal communication, February 25, 2019).
} 
how thesis writing in a Turkish university could be different compared to a US university. He recalls a conversation about a friend of his studying in Turkey telling him about his thesis topic and the organization. His friend had no idea as to what to write about at first and his professor told him to just write about one of the US president's foreign policies, which Murat sees as 'meaningless' as it does not add anything to the field but just repeats the previously done or already existing work, and how it would be unacceptable here in the US or within his own standards of producing academic work, because to Murat, an academic work, especially a high-stakes one such as the thesis, should not be a repetition and a compilation of the existing sources, but instead, it should include an original idea that comes out of synthesizing all the sources available to you. He repeatedly emphasized the value he gives to originality in his work and he also expects to see it in whatever he reads, too.

In that sense, Murat is highly aware of the rhetorical contexts he is in, the languages he uses and how he uses them based on the requirements of the academic discourse, but he also keeps his own stance and style in participating in scholarly conversations.

\section{Abigail: 'We are constrained by the language we use.'}

\section{'Because of the unconfidence'}

Abigail had been in the US for four years at the time of the study. She is from China and she came to US for her MS degree in Finance, which was also what she studied in China for her BS degree. After she gets her master's degree in Anthropology, she plans to combine two of her majors, Finance and Anthropology, and calls this plan of hers 'just my small dream', signaling

her humility even at the initial stages of our time together. She uses social media in Chinese and 
communicates with her friends and family from China in Chinese whereas her daily language while in the US is mainly English. Her reading practices mostly consist of academic papers in English, for school work and rarely Chinese novels and not at all Chinese academic texts, except for the readings she does to learn a concept about her research. On the other hand, in terms of writing, apart from the regular school work with short papers and term papers, similar to Orsi, she also journals but only sometimes uses Chinese or a mix of the two languages, but she adds 'When writing diary, I prefer in English because those things happened in English context. I remember my feelings or ideas just automatically being pronounced as English in my mind. So, if I use Chinese, it would be like you're listening to a foreign movie and it's a mother tongue translation voice.' (Abigail, $1^{\text {st }}$ interview, January $23^{\text {rd }}, 2019$ ). When it comes to academic writing in English, she mentions that she forms sentences in Chinese mindset first, ' $[\ldots .$.$] but not$ the Chinese language.', and the same goes for her idea formation: '[ $[. .$.$] some big ideas I might$ form in Chinese because my research is about this phenomena in China.' (Abigail, $2^{\text {nd }}$ interview, January $\left.25^{\text {th }}, 2019\right)$. However, towards the end of our interviews, she also said:

'I don't have my voice in English, I think. [For Chinese] I'd give you a funny answer, but I think it's a true answer. Because I study English, my Chinese got messed and my voice in Chinese sounds silly and like 'You're not from here' in writing because sometimes I don't remember how to say this or I don't know how to say this - in daily stuff.' (Abigail, $2^{\text {nd }}$ interview, January $25^{\text {th }}, 2019$ ).

Being exposed to English this much and using it both to communicate daily and also for academic purposes, Abigail seems to have started to pay attention to her language use more. Not 
using Chinese as much as English now, she feels he is getting bad at her own language. For written language use, though, she says: 'Even though I'm not so much of a confident person, I actually wouldn't call myself a bad writer. I think I can at least write clear things.' (Abigail, $1^{\text {st }}$ interview, January $\left.23^{\text {rd }}, 2019\right)$. However, she shows humility in the way she talks about her writing abilities because in more than once instance she talked about how she does not see any strengths in her writing or that it is hard to find them. She says:

'I'm not confident in English writing. Even though the professors here are mostly nice- they say this is good writing, I know they're being encouraging and I appreciate and am encouraged by it. This self-unconfidence [pauses]. I don't mind being not so good at English.' (Abigail, $1^{\text {st }}$ interview, January $23^{\text {rd }}, 2019$ ).

The more we talked about this issue of being unconfident, the more clear it has become that her lack of confidence in herself especially in writing results from her lack of knowledge in the content she is writing about. She says:

'Even though I have done research, I still feel unconfidence. Maybe what I write can be challenged. Maybe other people are going to point out. Now I see it's definitely what's going to happen, but I have to proceed with what I've already researched I guess. But that kind of fear or unconfidence is always there. I think it comes from [pauses]. I try to write things that are accurate, flawless but definitely it could be flaws.' (Abigail, $1^{\text {st }}$ interview, January $\left.23^{\text {rd }}, 2019\right)$. 
The flaws she talks about are not related to her language abilities, though. She says those can be fixed, so she cares more about the ideas she presents. In that sense, she seems like Orsi, who is also afraid of being challenged by the readers in the content they are presenting. But for Abigail, trying to write 'accurately' or 'factually' is a strategy she uses to avoid being judged and therefore she emphasizes over and over the importance of writing clearly.

\section{Reader Conscious Writer Identity}

One of Abigail's favorite aspects of writing is her ability to communicate clearly via writing. Regardless of the language she uses, she reported that her writing is always more clear compared to her spoken communication. Especially in English speaking contexts, she says if she feels impatience even just a little, she would worry about not expressing herself clearly. 'That's why I say writing [is] more clear because I am given time to say all I want. Also, atmosphere: if I'm not familiar or there's a distance there [among people], that's limitations.' (Abigail, $1^{\text {st }}$ interview, January $\left.23^{\text {rd }}, 2019\right)$. She also emphasizes how she worries about wasting other people's times if she forms long and elaborate sentences, especially during class discussions, and therefore, she uses short sentences or even just key words as the best way 'to throw out ideas'.

When it comes to writing, although she sometimes forms long and vague sentences, a result of being influenced by the reading a lot of English academic texts, she says, ' $[\ldots .$.$] where$ the writers write long and complicated sentences' (Abigail, $1^{\text {st }}$ interview, January $23^{\text {rd }}, 2019$ ), making her think that it is the way to write professionally and academically, she seems to show awareness of how it might be taken up by her readers as unclear. She says 'In my heart, I know it's just because it is long' because at times she also uses writing to figure out what she really 
wants to write about or to figure out her own stance in the subject matter- using writing as a tool to generate ideas (Abigail, $1^{\text {st }}$ interview, January $23^{\text {rd }}, 2019$ ).

Her emphasis on clarity of ideas presented through writing is also demonstrated in the ways she describes who is a good writer and what a good academic writing looks like.

'So far by my experience, I really appreciate when writing is so clear. The idea could be complicated but writing could be simpler and clearer. I guess I am thinking of this for international students and readers. Because as native speaker, it's not that big of a problem, but for me, it could be just a bit easier to read. I'd feel so much encouraged to engage in reading. So, I think a good writing should be concise and sharp- to the point. [....] Being confident is also a good quality a good writer should have now that we talked about it because really a writer should be confident about what he or she has said- as long as you believe you are correct, other people would, too.' (Abigail, $1^{\text {st }}$ interview, January $\left.23^{\text {rd }}, 2019\right)$.

Considering her own identity as an international student consuming academic texts in English extensively, she appreciates a simpler language use in these texts and clearly articulated ideas. That is also probably why she tries to write clearly herself, thinking of her audience. However, she also mentions that she thinks there are two different kinds of writing: '[One is] more emotional and one is more describing facts and arguments. I think I'm better at this objective writing, in arguments. For personal writing, I'm not good at it.' (Abigail, $1^{\text {st }}$ interview, January $\left.23^{\text {rd }}, 2019\right)$. At another point during our interview, she had talked about the reason why she thinks so of her writing. She seems to think that her personal writing, journaling, lacks structure 
as she writes without thinking about how to organize her thoughts but more in order to record what happens in her life. Therefore, with academic or 'objective' writing, she feels more comfortable because she outlines what she is going to write about and supports her arguments with other sources, making her writing more 'solid' and 'full of facts' to avoid criticism or judgement from her possible audience.

In addition to her concern for the audience, in personal writing, she also seems to be fearful of being limited in the way she could express her feelings. She stated that feelings are so vague and therefore harder to express:

'There is this big word 'happy'. No matter Chinese or English, but happiness are different in different kinds. So I don't know how to describe different happiness. Different things give me different happy feelings. The feelings are different happy feelings. Some happiness are very exciting and [some are] very warm, and some happiness are maybe [pauses]. That's when I'm stuck. [I think it is because of] the range in feelings. Or your different feelings for different people: Different closeness or just different perception. I sometimes say 'a nice person' [but it] may mean different nice for different reasons. [.... There is this Linguistic Anthropology and with that I can see how language can shape different ideas, and sometimes, we are constrained by the language we use.' (Abigail, $1^{\text {st }}$ interview, January $23^{\text {rd }}, 2019$ ).

Her insights about how language shapes our thinking is also a well-documented phenomena through Sapir-Whorf hypothesis, reminding me of a study an Anthropologist, Lera Boroditsky, conducted with different speech communities around the world, to reveal how everyday 
incidents like greetings, describing events or differentiating colors differ in every language due to certain such concepts existing in these communities as use of directions or grammatical gender (Boroditsky, 2018).

Besides the difficulty in expressing feelings, Abigail also talks about what she calls 'cultural context translation'. When I asked her to explain what she exactly means by that, she said: 'For example, in certain cultures, [there are] some certain words in your mother tongue that couldn't be translated- it would be really hard because of the cultural difference.' (Abigail, $1^{\text {st }}$ interview, January $23^{\text {rd }}, 2019$ ). She expanded on it with an example, the word 'farmer' in English. She says it has a different meaning when used in the US context, with the image of a farmer being different here because of the specific background, when compared to the image it would create in people's minds upon hearing it in China or Chinese. 'When translating, they are the same word, but I know they actually are not.' (Abigail, $1^{\text {st }}$ interview, January $23^{\text {rd }}, 2019$ ). With such reflection on the use of even the daily words, she signals her understanding of how differently these two languages work, even in the minds of the users. To this end, the role of language in constructing and retaining knowledge (Harrison, 2007) becomes apparent when she says: 'Writing is how other people know what you're doing' (Abigail, $1^{\text {st }}$ interview, January $23^{\text {rd }}$, 2019).

\section{Writing Sample: Ideational and Interpersonal Evidence}

What Abigail chose to bring as her written artefact was a draft of her thesis proposal written the semester before in one of her courses, similar to Orsi's. Combining both of her interests, she picked the topic of microfinance and its social influences in China. Her title is 'Reexamining Microfinance: Is It Helping Borrowers in Rural China?'. She wanted to write on 
microfinancing in rural China after reading about similar approaches in other countries and how they influenced the people in areas of poverty, especially in rural China, her home country. She discusses in her paper that borrowers may face certain social and cultural complexities in their financial activities through microfinance strategies targeting them. In that sense, it is a highly critical text and she presents her arguments in various ways.

To begin with the way she forms her arguments throughout the paper, we can see that she approached this type of writing as 'objective' as she calls is rather than 'personal-emotional' writing, where she presented facts and arguments of opposing sides in which she also made apparent her stance. However, she also mentions that even in her abstract, given in the excerpt below, she includes her 'subjective judgement' by purposefully putting the word 'consciously' in parentheses:

This reexamining aims to foster a better understanding of the influence microfinance has on borrowers whose risk might be unconsciously (or consciously) ignored by designers of these programs.

In line with her emphasis on clarity in arguments in an academic paper and how important it is, she also follows her own advice and gives her stance evidently through her specific language use. For instance, she only uses present simple tense and avoids using any hedging as she is only sharing 'factual information'. In doing so, she first presents the opposing ideas, then continues with her own claim by using 'however': 
Throughout these studies, there is an assumption that microfinance can be a successful financial product based on social trust. However, the cultural and social complexities embedded in the practice of microfinance are often overlooked in this economic assumption. (Emphasis mine)

Since microfinance carries the aim of social empowerment for the conventionally marginalized people who have had no access to regular bank loans, there have been proved success on social empowerment in creating economic opportunities for the poor (Yunus 2017). However, the aim of social empowerment and the actual impact of microfinance do not always match. In fact, the optimism in microfinance that was high from the late 1990 to the mid 2000s took a reverse turn the same time of 2008 financial crisis. (Emphasis mine)

Many financial inclusion projects and initiatives are being carried out with great enthusiasm in recent years (Li 2016). However, the subjects in the mechanism of microfinance - borrowers, usually the rural Chinese villagers, are not the subjects given sufficient consideration in the microfinance product design. (Emphasis mine).

Additionally, even though she kept emphasizing during our interviews that she 'indirectly uses criticism' in her paper (Abigail, $2^{\text {nd }}$ interview, January $25^{\text {th }}, 2019$ ), even from the above examples we can see that she is actually being quite open about her stance in the subject matter. In doing so, she uses certain boosters- linguistic acts that allow expressions of 'certainty' (Hyland, 2005)- such as 'These risks may reflect complex social and cultural contexts that must 
be taken into account if microfinance is to achieve its goals.', 'Social relations and dynamics cannot be ignored while measuring social empowerment because economic development is only one dimension of an individual's life even though it is a critical one.' and 'Meanwhile, many unnoticed stories on the ground level of microfinance practice needs to be heard and studied.' She also frequently makes use of 'will' to show certainty as in 'The effort in reexamining microfinance will show the importance of taking social implications into account when designing economic mechanisms for the poor in the future.' , '[....] these impressions will determine not only the orientation policy-makers have when designing, but also the actual practices of officers from these institutions to have on borrowers.' or 'The entire calculation will be justified by the rural Chinese villagers' value system but it won't be the same for microfinance institutions when they make general assumptions about lending.' (Emphases mine).

Her overt criticism in writing, in that sense, could be interpreted as false humility. Although she repeatedly mentioned that she tries not to be overconfident in her arguments in writing as she has concerns about her lack of knowledge and thus confidence in the subject matter, her writing proves otherwise as can be seen from the examples above. With her writerly identity contradicting what she says, she shows that humility differently from Orsi, who calls herself humble but she recognizes the fact that her writing suggests the opposite, maybe due to her immersion in the English academic culture more than Abigail who has been in the US only for a couple years. It seems to me that the way Orsi resists her professor's suggestion in changing her text to exclude her experiences is related to her seemingly assertive writing identity which she calls activist. For Abigail, I feel that she may not come across as fully aware of her writing self in that she does not recognize the linguistic acts she makes use of to actually use overt criticism which she so desperately tries to avoid as she mentioned in our interviews. 
Her lexical choices in certain strategic places are another indication of her open criticism. However, she says she has employed some acts to put her ideas in the text through such strategic moves as using critical words and phrases, with quotation marks to show irony, or personal asides to demonstrate that she does not actually agree with the ideas given (Abigail, $2^{\text {nd }}$ interview, January $\left.25^{\text {th }}, 2019\right)$.

The belief and presumption from economists' view has long been that microfinance is a solution to poverty alleviation [....]. Seen as a one size fits all model, it has ignored the subtleties of communities, [....]. Specifically on the mechanism design for risk management, it is believed that individuals are incentivized to pressure group members $[\ldots . .$.$] . (Emphasis mine)$

Other "borrowing guarantor" stories further illustrate the additional social risks forced on women while such mechanism is claimed to have social empowerment for women. (Emphasis mine)

Is microfinance really helping the borrowers? The importance of answering this question is not only about revisiting the assumptions made in risk management principles [....]. (Emphasis mine)

In fact, she uses the word 'assumption' quite a lot in her text to show how doubtful she is about the benefits of microfinancing in certain situations, including but not limited to the following: 
In this paper, I examine the assumptions made regarding social relations in microfinance, the practices of microfinance that create new social dynamics, $[\ldots .$.$] .$ (Emphasis mine)

Throughout these studies, there is an assumption that microfinance can be a successful financial product based on social trust. (Emphasis mine)

$[\ldots$.$] little research has been done from an anthropological perspective to reexamine$ assumptions embedded in the risk management practices carried out by the microfinance institutions, [....] (Emphasis mine)

$[\ldots .$.$] (which is an assumption that farmers are in need of financial education which$ the policy makers think as a necessary skill today) etc. (Emphasis mine)

Another word she commented on as an indirect way of criticizing microfinance practices was 'dilemma'. In her literature review, there is a section titled as 'Dilemmas in Microfinance' and when I first asked her about her word choices and the connection between critical ideas she presented in the paper, she immediately went to that section. She said: 'I don't actually know if dilemma is the right word here, but I like how it represents what I want to say. [....] So, microfinance aims to do good for the people but it actually has some risks for people. That's why it's a dilemma. I think it's already a critique, right? Putting it right there in the title?' (Abigail, $2^{\text {nd }}$ interview, January $\left.25^{\text {th }}, 2019\right)$. 
She also consciously uses quotation marks for words and phrases such as 'backward, in need of education, modern' to criticize this labeling from the opposing side to her arguments:

In this context, rural China is considered to be the "backwards" in the modernization progress.

The notion of "advancing" and "credit consciousness" is often connected with moral traits such as "honesty" and 'trustworthiness' which inculcates farmers to be more “modern".

Looking at the borrowers as "in need of education" automatically pose these institutions at privileged position which lead to neglect of asking question if borrowers have really been helped by microfinance, $[\ldots .$.$] .$

Another technique she utilizes to critique or add her own stance is a personal aside by using parentheses. For example:

The scholar discussions about microfinance in China are mostly around how to control the credit risk (which is against borrowers failing to repay the loans), how to increase or balance the demand of credit in rural China (He 2008) (implies the idea to deepen the financial services to a larger scale to expand credit market), how to increase the farmers credit consciousness (He et.al 2009) (which is an assumption 
that farmers are in need of financial education which the policy makers think as a necessary skill today) etc.

This reexamining aims to foster a better understanding of the influence microfinance has on borrowers whose risk might be unconsciously (or consciously) ignored by designers of these programs.

Unlike Orsi, though, Abigail does not use self-mention to position herself in the discussion, but, as can be seen from the above instances, she does show her stance through clear structural and lexical moves in her writing. In addition, her attitude markers also complement the way she poses her arguments throughout the paper. In line with her word choice examples given above, she also uses the frequent structure of 'It is important/inevitable/necessary/imperative to notice/think/rethink/reflect [....]' to bring attention to the essential actions that need to be taken and reconsider the risks of microfinancing- which is where her arguments lie.

In sum, at the ideational level, she presents her ideas clearly and makes her stance known even from the beginning, and does so through mostly her lexical choices. Besides that, her stance is highly critical of the existing financial practices and therefore, in an effort to persuade the reader, she constructs her sentences in a very firm manner. Although she acknowledges the opposing perspectives and shares their arguments in her paper, she uses them as a stepping stone to indicate where she stands. To do so, she frequently uses present simple tense as she believes she is presenting facts and organizes her paragraphs internally consistent.

At the interpersonal level, to engage with her readers, she only uses the question in her title within her text once (Is microfinance really helping the borrowers?) and then goes on to explain 
how it may not, and she tries to write 'factually' to avoid harsh criticism from opposing sides. Since she is criticizing mostly the economists using the financial models she talks about in her paper, she considers them as her audience:

'[....] there's no obvious or direct word that carry the tone of criticizing or being very critical but this whole sentences actually mean that these economists actually ignore something important. That's my critique [because of the words 'presumption' and 'ignore']. Also I try to be, I wouldn't be too harsh or so confident in saying 'All the economists..' I wouldn't say they are wrong or did something bad because I'm afraid I am wrong. [It's because of my] unconfidence, but also I was reminded that I need to recognize what other people have done- I did it later. I see the whole picture, I see what you've done, but there's something wrong.' (Abigail, $2^{\text {nd }}$ interview, January $\left.25^{\text {th }}, 2019\right)$.

When I asked her even though she had done all this research and seen the risks related to their models, if she still felt uncomfortable saying it directly, she said: 'Yes. But also the mainstream of microfinance is occupied by economists, so I guess I am influenced by the whole power of that discipline and that's why I value and appreciate Anthropology because you see [what] economists ignore, but I admit that it's hard to challenge.' (Abigail, $2^{\text {nd }}$ interview, January $25^{\text {th }}$, 2019). So, even though she has a background in finance, she still feels a lack of confidence in criticizing the economists directly here. She does not feel confident in the content and is highly aware of the social power dynamics at play and therefore places herself carefully in the discussions surrounding her topic. 
Additionally, as we talked more about open criticism in writing, she began to think about her habits coming from being raised in Chinese culture. At some point she said:

'Because of Chinese culture, if I have any sentence really really assertive and sounds too certain [pauses]. I mean listing a fact is okay, but if it's an opinion and if it sounds too assertive, in Chinese, because of my Chinese background culture, I would change it to be less assertive. Still it's a for sure sentence but wouldn't sound overconfident. [....] In Chinese language, there are ways to say the same thing but using a softer wayhow you compose the sentence. For example, 'ignore', even though it's not a good example here and I don't think there's any problem here, I could say instead 'not take into account' and it would be softer.' (Abigail, $2^{\text {nd }}$ interview, January $25^{\text {th }}, 2019$ ).

With this reference to her culture being an influence in the way she forms her arguments or criticisms, she is similar to Murat, who also mentioned not being very comfortable criticizing within his own culture someone who might be socially or hierarchically in a higher or more esteemed position than he is. In that sense, '[....] what is said and not said is purposeful' as '[....] language operates within relations of power' (McKay, 2013, p. 29). Therefore, they cannot express themselves in a very evident manner in their writing, thinking about the social boundaries they perceive among their discoursal circle. This could be related to the fact that they are new to their respective academic communities, but also, it is important to note that this could stem from their cultural upbringings which could be impacting how they act in a certain way, as both of them clearly mentioned during our interviews- with Murat, though he stated that in a hypothetical situation where he wouldn't 
be able to criticize a Turkish professor or in Turkish academic context as he should be showing respect to them due to their social positioning, and with Abigail, as we can see above, she thinks she needs to adapt her language to be less assertive as her culture demands it that way- for her to be more 'humble' in presenting her stance.

Moreover, her role as a first year master's student also influences her writing. She says she inherently tells herself that she is 'just' a first year master's student, a new researcher to this topic and that she '[....] should be careful as to not make too affirm judgements' (Abigail, $2^{\text {nd }}$ interview, January $25^{\text {th }}, 2019$ ). She adds: 'As a student, it definitely influence[s] my attitude of being modest. [....] Right now identity of being a student and being a female definitely influences the tone. I don't specifically see it in my writing here but as a Cultural Anthropologist, I know it [being female] certainly has influence on our choice of using words and attitudes of just how to approach and how to talk to people $[\ldots . .$. . To me, [influencing] writing not too much but maybe it's there, but I don't see it.' (Abigail, $2^{\text {nd }}$ interview, January $25^{\text {th }}, 2019$ ).

As a humble graduate student, Abigail presents herself as an 'unconfident' writer, especially if she is not writing 'factually'. At the end of our interviews, she also added as a side note to me that she never diverges from the expectations of an academic writing situation and that she always follows the guidelines to not take any risks. She says: 'I always follow the more experienced and more authoritative voice or suggestions. Very little things that I know wouldn't matter.' (Abigail, $2^{\text {nd }}$ interview, January $25^{\text {th }}, 2019$ ).

\section{Common Themes in All Three Cases}

Based on the primary research question regarding the discursive features multilingual mature writers across disciplines use in their academic writing for self-representation, taking 
Matsuda and Tardy's (2007) explanations of what discursive and non-discursive acts entail, I will now present what common themes emerged in all of my research participants and also interpret the data taking into account the ways how they negotiate different aspects of their identities in academic spaces they are a part of- as part of my second research question. What Matsuda and Tardy mean by discursive features in writing is two-fold: one related to the forms and the other content. The form includes areas such as sentence structures, organization, transition devices ${ }^{4}$ and word choice, while content includes topic selection, use of examples, and argumentation strategies.

To begin with the discursive acts related to form, both the interviews conducted and the textual analyses of their written artefacts have showed that all three writers frequently make use of present simple tense to present either factual data or their own arguments. For Orsi, using present simple tense is a way to show her confidence in her own arguments as she is more confident in writing than spoken communication, and she uses such sentence structures to form direct statements. Murat, on the other hand, has some confusions at times as to what tenses to use and therefore chooses to have present simple tense so that he can have consistency. Similar to Orsi, Abigail is more confident in her written communication, and therefore, presents her ideas in a factual manner through present simple tense, since, to her, it seems like the best way to be objective. Another common sentence structure they demonstrate, though some not particularly in the writing samples they provided for the study, is mentioning passive voice in forming sentences. In their academic writing trainings, either in high school or during their undergraduate years, they all stated that they had been taught to use passive structures to have a more formal tone in academic writing. Therefore, they pay special attention to have more passive sentences

\footnotetext{
${ }^{4}$ The use of transition devices was only observed in Murat's case, therefore will not be a part of the discussion in this section.
} 
throughout their writings. This often results in long sentences in their writing, though it is not the only reason for it, something both Murat and Abigail have had feedback on from their professors, so, they try to balance that in a specific writing assignment based on the comments they receive. However, even though in the interviews they suggested that, their writing sample analysis showed that they do not in fact make use of passive structures that frequently (if any) in their writing.

When it comes to organizational choices, all of these three multilingual writers usually make in their academic writing in the graduate school in the US, what stands out is the way they integrate opposing views in their argumentations and criticize them. In that sense, what I have observed is that, all three participants first talk extensively about the perspectives they oppose to and then present their arguments and criticisms of those views and then support their own stance in the matter through other resources. They all emphasized in our interviews that it was really important for them to talk about different aspects of the issue they are writing about and defend their sides by either refuting the opposite ideas or showing the opposing sides how there could be more to what they argue. Although Abigail stated that she was not being direct in her criticism, her writing sample analysis revealed the opposite. In that sense, both Orsi and Murat, who mentioned that they are direct in their criticisms, and Abigail, who is indeed direct and clear while she presents her perspective in writing, make use of outside sources and different sides of the subject matter being discussed in organizing their ideas in a paragraph.

Lastly, in terms of the word choices, all participants mentioned their concerns about the limited use of vocabulary in their writing and trying not to have a lot of lexical repetitions. However, their concerns were for different reasons. Orsi stated that she lacked relevant academic and discipline related vocabulary; for Murat, feeling inadequate in his lexical knowledge was due 
to his using other languages in trying to translate certain expressions into English which may not always have a direct correspondence, i.e. his lack of command in English expressions and even grammar; and lastly, for Abigail, the language itself is limiting in the way that it cannot always capture the concepts she tries to convey, as in the case of feelings such as happiness. Another prevailing aspect in all participants' word choice was related to the attitude markers in representation of their stance in writing to convey their affective commitment to the subject matter. In that sense, both Orsi and Murat had extensive use of adjectives to support their own arguments or criticize others', and for Abigail, it was mostly to complement her own arguments.

Overall, then, in the way these multilingual writers use textual acts related to form in negotiating their identities in academic writing, they demonstrate their stance through clear and direct sentence structures and by use of word choices that reveal their affective positions. In doing so, though, they show how much they are aware of the linguistics choices they make within the text and do not refrain from arguing for what they believe in writing- expressing confidence in their arguments and in the subject matter being discussed.

The negotiation of their identities as multilingual mature writers who make use of varying linguistic resources at their disposal as well as making use of their unique backgrounds as language learners is not limited to how they form their sentences. In fact, their selfrepresentations can be observed even more clearly on the content level of discursive features in their academic writing.

To begin with the topic selections in their papers, especially for the ones they chose to bring for the study, they all picked what they wanted to write about- except for Murat who wrote a book review but for him, how he actually wrote the review in terms of its content was also different from what was expected, so, we can still say their they all used their agency in that 
sense. Both Orsi and Abigail wanted to choose a topic that was relevant and meaningful to them for their probable master's thesis for the coming year, and for Murat, the book was chosen by the course professor, but when I asked him his usual practices for choosing topics for his papers, he mentioned that he usually decides to write a paper on what looks like a necessity in his fieldwhat has not been studied before or from a perspective he presents it. In that sense, they all value originality in their written productions- with Orsi it is through talking about non-profit organizations and especially her own choosing of one specific organization; for Abigail, she is focusing on rural China, having come up with the idea after reading similar studies in other parts of the world, and for Murat, if he reads about a historical event or some relations among different countries and if the topic is of interest to him, he decides to write about it through Turkish [government] perspective, which lies within his academic interests. Therefore, they not only come up with topics to write about based on their interests, but also, they make use of extensive research to present their ideas.

Valuing good research, in that sense, is another common feature of their academic writing observed through our interviews. They relate good research to originality and often rely on external sources to back up their arguments. From what I gathered during the data collection and analysis process, it has become clear to me that for Orsi and Abigail especially, this results from their lack of confidence in the content knowledge. They both stated their concerns about not covering everything that is needed to be covered repeatedly. In that sense, Murat seemed more confident in his research skills. Similarly, fearing harsh opposition and criticism from different communities, both Orsi and Abigail tend to rely on external resources to support their stances. However, this does not mean that they do not include any of their own experiences in their research papers, which actually brings us to the next common feature observed in their academic 
writing practices. They not only use examples from external sources, but they also make use of personal accounts in their writing for different reasons. This often seems to result in a narrative style in combination with the academic. For instance, while Orsi specifically talks about her own experience in AmeriCorps to solidify her arguments, resisting the comments from her professor who suggested her to take that part out, for Abigail, talking about her experiences in China at the beginning of her paper helps her organize her paper better even though she stated that she would take that part out when she would turn the paper into her actual thesis. Murat, on the other hand, has a more professional approach to using narrative style as it is a highly accepted style of presenting historical events in his field, which is why he balances professional writing with what he calls storytelling to increase readability. Therefore, we can say that such an approach to presenting their ideas, they negotiate their stance with the immediate readers- professors-.

Thinking about their readers, they all stated their concerns for other possible audiences for their work and how they impact their argumentation strategies to a great extent. Fearing harsh criticism, both Orsi and Abigail think as their ultimate audience for their thesis proposals corporates and economists, respectively. Not being very confident in presenting every side of the issue in their papers, they rely on presenting what they know and have researched in a clear and direct manner. Murat's concern, on the other hand, is related to reaching out more readers by integrating his arguments in narration rather than having a purely factual writing. Therefore, we can say that they are all concerned about ambiguity in their writing, which is a challenging aspect for them for varying reasons and they all overcome the issue in different ways. Overall, though, what I have observed in all participants is that their identities play a huge role in the way they choose and deliver their content. Orsi is humble and introverted but in writing a great activist arguing for what she believes. Murat predominantly chooses to write about topics that 
are meaningful and relevant to him and does so his way by mixing narrative with professional writing style. Abigail, though follows instructions and requirements of any writing situations and fears risks, is highly aware of her audience and rhetorical situations and delivers what she argues for clearly by relying mostly on factual information. In addition, their linguistic and cultural backgrounds are also in effect in the way they form their arguments or use criticism. Murat talked about how writing with a critical tone would be hard in a Turkish context as he would have to be 'respectful' of the social roles involved and the power dynamic between him and the immediate readers, professors. For Orsi, resisting the comments from her professor actually seems to demonstrate her 'American' side even though she kept calling herself 'humble' in spoken communications. Similarly, Abigail kept signaling her humility throughout the interviews, pointing to her cultural upbringing which directed her to soften her arguments in writing- which were indeed overt and had an assertive tone, letting me think that she was not aware of her won confidence or language use or tone in criticism in English or the possible differences in the way criticism is displayed in Chinese and English academic writing. To this end, the representation of the writerly identities of all three participants showed a close connection between their existing and changing languages and cultures.

When everything is taken into consideration and thinking about all these different ways of self-representation in academic writing, being aware of their linguistic resources and considering the audience for whom they are writing to and what they are trying to achieve through their writing, these multilingual writers who come from varying backgrounds and who have their own unique combinations of identities give hints of who they are as individuals in their writing through textual features often revealed in such discursive acts as writing style, topic selection and lexical and grammatical choices. 
To summarize, then, the findings of my study center around three major themes: (1) The disciplinary voices/identities of my participants, as evidenced from their discursive choices, are mainly demonstrated through their linguistic and thematic acts in their writings. (2) Their argumentation styles in academic writing is influenced by their linguistic, cultural, and both inschool and out-of-school literacy experiences to a great extent. (3) They make use of personal experiences and/or narrative style in their academic writing practices as part of their dual identities as emerging scholars and multilingual and international graduate students.

In the following chapter, drawing from the findings discussed in this section, I will discuss some of the pedagogical implications of my study in two parts; from the institutional and instructional support perspectives in an effort to help offer some suggestions regarding multilingual graduate students across campus to better their academic writing experiences. 


\section{CHAPTER V: PEDAGOGICAL IMPLICATIONS}

\section{Introduction}

This study investigated how multilingual graduate students across disciplines in the US universities represent their voices and multifaceted identities in disciplinary spaces through their academic writing. In this regard, drawing from previous research on voice and identity issues in second language writing, the case studies at hand responded to the following research questions: (1) How do multilingual students negotiate different aspects of their identities in their academic writing practices?, and (2) What are some of the discursive acts they use in writing as a way of self-representation?

In this chapter, I will discuss how the findings can influence the pedagogical approaches that could be developed or used when it comes to working with international graduate writers in academic spaces. By responding to the findings of similar research studies in the field of second language writing in graduate programs, I will explore the implications of the findings and provide recommendations for institutional and instructional practice.

\section{Overview of Findings in Light of Existing Research}

As given in detail in the previous chapter, when I looked at the form and content related issues represented through our interviews and also with textual analyses of the written artefacts, what I have reached at is that my multilingual participants value directness, objectivity and clarity in their writing in English as a second language in academic spaces. They also use argumentations through criticism in their work but do so fairly in that they include different perspectives extensively before arguing for what they believe in. In doing so, to become a legitimate member of the academic discourse community in their respective disciplines, they 
make use of evaluative markers in their writing to show their stance in an effort to position themselves in the academic conversations. They tend to do so by mostly bringing in topics they are most passionate about- topics that are relevant and important to them for various reasons. In presenting their ideas through research and personal experiences, they rely on their existing world knowledge acquired through exposure to different ways of knowing both through their educational backgrounds and interactions with people who might have non-western values and non-English languages as well as new disciplinary knowledge they build in their current studies in the US. In summary, they engage in various discursive acts in their writing and in doing so, their unique combinations of identity aspects are at play to a great extent as they all want their voices to be heard as resourceful individuals who are finding their ways in the US English academic spaces. However, they didn't seem to feel they could so freely claim 'ownership' of this diverse knowledge- hence the frequent emphasis on humility throughout the study by especially two of the participants. In that sense, drawing from their linguistic, rhetorical and experiential knowledge and resources, they make certain linguistic moves to fit in with their academic communities they are about to be a part of while at the same time demonstrate their individuality in their textual choices.

The findings of this study resonate with similar studies on voice and identity issues in L2 writing (e.g., Hirvela and Belcher, 2001; Ivanic and Camps, 2001; Matsuda, 2001). For instance, Hirvela and Belcher in their study acknowledged that multilingual graduate students already come with a wide range of professional and academic experiences in their other languages and in the other cultures they lived in that they have unique voices when they compose texts in English academic writing, as well. These previous writing experiences, whether in professional settings or done for personal reasons, have influences in the way how these individuals transfer their 
skills and knowledge in new writing situations. In that sense, we can see a blending and mixing and matching writing practices that are highly creative approaches observed with multilingual writers who can disrupt the static understanding of 'disciplinary dress codes' (Ivanic and Camps, 2001, p. 21), as in the case of Orsi who was writing journals and using Hungarian at times, and Abigail keeping a diary in English to record what happens in an English-speaking context, and Murat publishing in English in his home country as a $\mathrm{PhD}$ student. Their antecedent experiences with writing, in different genres and languages and cultures come as resources in the way they approach English writing in the US, which was also the case in Seloni's (2014) case study of a Columbian graduate student who was a professional curator before coming to the US for a graduate program. His writing identity was also influenced by his professional background and he was not shy in using that, and because academic writing in his second language was a relatively new area of exploration for him, he integrated his writing experiences into his thesis writing as a way of owning his texts. However, in certain cases, depending on many factors including the disciplinary expectations regarding academic writing, multilingual students can experience what Hirvela and Belcher call 'painful disciplinary acculturation' (p.86), especially when there is not a clear match in expectations, resulting from a culturally biased approach to writing in academese. In that sense, many multilingual graduate students who are not trained in 'inner circle countries' (Kachru, 1985), where English acts as the first language, have to adjust to a new identity and 'balance new identity with the old' (Hirvela and Belcher, p.86). From what I gathered through my interviews with my participants, I have also seen that all of my participants try to balance their student and emerging and novice scholar identities in this relatively new academic context. Orsi is empowered by writing in the sense that she is more confident in arguing for what she believes through writing and presents her ideas clearly and openly unlike 
her spoken conversations; Murat uses a narrative style in his academic writings as a way to represent himself and his style with the readability of his papers in mind, and he is confident in criticizing other scholars in his work; and Abigail considers herself as 'just a student' but frequently uses overt criticisms in her writing, similar to Murat and Orsi, as she sees academic contexts as suitable for such acts. In this regard, as Ivanic and Camps (2001) argue, these writing practices have an integral part of negotiating identities. In all of my observations and analyses, I have seen that the multifaceted identity aspects my participants have influence the way they represent themselves in writing both in the content and the delivery strategies they choose. And they do construct these self-representations 'from culturally available resources' they have (Ivanic and Camps, p.5). What these multilingual writers and emerging scholars value and what they believe in as well as what they prefer indicate clearly their stance through their use of 'evaluative lexis' (p.13) in their disciplinary writing, which is evident in their attitude markers throughout their writing artefacts analyzed during the study. To this end, their discursive acts in academic writing reflect mostly their ideational stance and identity aspects that influence them, which is an important part of their voice in the second language. At the interpersonal positioning, in relation to different degrees of self-assurance, certainty and power relationships between the reader and the writer (Ivanic and Camps, 2001), the ways they exert their multilingual writer and emergent scholar identities are represented through their opinionated sentences with first person pronouns usages, showing the 'presence of authorial presence', shaped also by social factors (p.26). In terms of the textual positioning of oneself in writing, the linguistic choices made by the participants demonstrate that they have awareness of the importance of clarity, cohesion, and coherence in English academese as they have shown a 'reader considerate voice' (Ivanic and Camps, p.29). Therefore, unlike Matsuda's (2001) study where his Japanese participant who was 
not familiar with the strategies in English had difficulty in writing, my participants were all mostly familiar with the reader and disciplinary expectations due to their educational backgrounds, in a way showing the prevalent emphasis given to English style of writing/rhetoric both in EFL contexts (China and Turkey where Abigail and Murat had their first encounter with it) and in the US high schools and universities.

\section{Pedagogical Implications}

My analysis and literature review, as well as my own experiences both as an international multilingual student and as an emerging scholar, along with my experiences in teaching academic writing to the speakers of other languages, have directed me to focus on two aspects in this section, namely on institutional support and instructional support for international students across disciplines. $^{5}$

At the institutional level:

- Graduate writing courses can be offered as a requirement in first year of study in each discipline, both for master's and doctoral level, not to 'just get it right' but to create safe spaces for academic literacy and academic socialization and to increase participation and investment in academic discourse community.

- Weekly/Monthly support group meetings or regular cohort meetings can be held to share experiences as graduate students, writers and even instructors in and beyond each discipline to provide spaces for negotiation of changing identities as emerging scholars.

\footnotetext{
${ }^{5}$ I acknowledge that there is much more to explore in these areas that I cover in this chapter, but I just wanted to give a short overview of what could be useful at the immediate level to cater to the needs of multilingual graduate students.
} 
- More writing support can be provided in the form of tutoring sessions in Writing Centers for not only undergraduate students but also graduate students- with specially trained graduate tutors for international students and not just for language related issues but also rhetorical and discipline-related expectations.

- Professional trainings can be organized across campus and across disciplines as well as in-house trainings to address diversity, multicompetence and translingualism of students to increase collaboration and awareness/understanding as well as to increase awareness of the faculty on how multilingual writers engage in academic literacy practices so that they can provide better feedback and response to their writing.

At the instructional level:

- Formal and/or informal, (semi) structured platforms for academic engagement can be used to help students bring in literate activities outside of school contexts to increase engagement and to increase academic socialization for those who might be better at lowstakes written communication ways.

- Creating writing/writers workshop sessions for peer response and feedback can be held at least once before each major assignment is due in disciplinary courses.

- Creative and alternative expressions of selves in writing which can appear in language use, genres, content, rhetorics, themes or even research methods should be allowed (i.e. genre innovation/play that can lead to a blended/hybrid scholarship)

- $\quad$ Through translingual approach, purposeful language play should be allowed and negotiations of meaning though one-on-one conferences or simple in-class dialogues should be made possible. 


\section{Institutional Instructor Support}

\section{First-Year graduate writing courses}

One of the institutional spaces that graduate students can highly benefit from is graduate writing courses to be offered in each graduate program in the first year coursework plans. Both Abigail and Orsi stated in our interviews that they benefited greatly from the course they were taking in their first semesters in the Anthropology department, which focused on helping them through a high-stakes writing such as thesis proposal writing. Every week, focusing on one part of the proposal, they were not only able to manage the small writing tasks requiring different skills and approaches, but also they were benefiting from the opportunities of getting peer response along with feedback from their professors. During such sessions, though, the focus should not be on getting everything 'right', but there should also be room for negotiation of different ways of expressions as presented through writing. In that sense, if such a course could be offered in all the disciplines as a required course, both the international students who may have never engaged in such demanding academic writing practices or have done so in rather different circumstances, but also those students who are just acquainting themselves with graduate studies in their home country of US can ease in to the process and expectations of their fields and other academic discourses they are planning to be a part of rather than dealing with a sink or swim approach where they are thrown into highly demanding courses without much guidance as to how to navigate in a sea of academic register and unfamiliar knowledge construction ways in their respective fields. Also, while learning the expectations of disciplinary writing practices, students can also experience how to navigate the similarities and differences they are bringing to this unfamiliar community not only in terms of language but also rhetorical enactments as well as other acts of self-presentation. 


\section{Academic socialization and negotiation}

In order to improve the academic literacies of incoming students in the graduate programs and help them better socialize academically, offering such courses focusing on graduate studies and especially about writing at the graduate level is highly important. Allison and Harklau, quoting Short and Fitzsimmons (2007), explicate academic literacy as having to do with any reading and writing activity related to school work and any influence of out-of-school literacy practices, that varies in each discipline, which requires knowledge of several genres and awareness of rhetorical situations surrounding them, and as deeply influenced by 'students' personal, social, and cultural experiences' (2010, p.131). Therefore, what multilingual and therefore multicompetent students bring with them- their antecedent experiences and skills and knowledge they have built- should be used to their advantages in new academic spaces they are being a part of as they study at the graduate level. How these students view themselves and their 'capability as scholars and readers' influence how willing they are to participate in 'literacy activities' in the academic spaces (Alverman, 2003 in Allison and Harklau, p.139). To this end, Norton (2001) problematizes the dichotomy made when differentiating learners as motivated/unmotivated, introvert/extrovert or inhibited/uninhibited, saying that such distinctions ignore the affective factors, subjectivity, relations of power among the individuals interacting; and socially constructed ideas of self. Therefore, instead of oversimplifying the participations of international students in the scholarly conversations, framing subjectivity as multiple, dynamic, and contradictory, Norton suggests the term investment rather than motivation to talk about the multiplicity of the ways international students can partake in academic socialization. And in order to help students have more investment in their academic selves, we should provide safe 
spaces to exert their identities and be a part of academic socialization practices- however they appear to be in our institutions and classrooms. To become 'legitimate participants in their academic disciplines', then, graduate students need these 'safe [....] socialization spaces' so that they can also reflect on their participation and investment in the academic communities, which could be achieved through collaboration among fellow graduate students and/or interactions with professors or any outside classroom conversations (Seloni, 2012). When students feel safe to participate, they could be more willing to move away from imitating the existing practices towards a more individualistic representation of who they are in these new spaces more freely. To this end, while creating and expanding these safe socialization spaces, one thing to keep in mind would be to not overemphasize the gated practices by focusing too much on getting the genres or language use right and ignoring the individual expressions that might be reflected through divergences from these rooted understandings of how things work within an academic community because any unconventional usage or move could actually be where the scholarly or writerly identities of these students can be most apparent.

In her study of first year doctoral students in US where she studied the academic literacy socialization practices through a micro-ethnographic perspective, Seloni emphasizes that graduate programs are 'unique educational contexts where cultures and texts merge, creating alternative and diverse academic literacy practices (p. 47). During this merge, multilingual graduate students need to adapt not only the social academic spaces but also the linguistic environment that comes with it. Therefore, what Seloni presents as 'initial contact frames', which are 'interactive learning spaces $[\ldots .$.$] where students come into contact with academic$ knowledge or knowledge about disciplinary conventions' (p.51), and thus the discoursal language accompanying it, become key zones of academic socialization and acculturation. To 
create that safe zone that can also be formal and structured, having first year graduate acculturation courses where students can also come in contact with graduate level writing practices in their disciplines furthers the opportunities for students to invest in academic literacy practices.

Similarly, Yamada's (2016) study also suggests that students can greatly benefit from a long-term socialization process where they can get acquainted with the genres and other disciplinary practices, and a graduate course in each discipline, which can even extend to two semesters, can facilitate the thus needed academic and disciplinary socialization. Since graduate programs are spaces where alternative and diverse literacy practices merge, it might take more time for international students to find their ways around these spaces. Students' understanding of academic tasks evolve over time and therefore their performances and practices might differ (Kobayashi, 2016). Therefore, Kobayashi et al. (2017) suggest longitudinal studies to better understand the participation and transformations of these students (p.248). While these transformations occur, there might also some tensions due to a lack of agreement in the way students' assumed and ascribed identities, and their temperaments also play out as well as some strategies students make use of to negotiate their participation and positioning of their selves (Morita, 2004; 2009). Hence, to avoid or lessen these tensions regarding a mismatch of expectations, before these graduate students are fully immersed in their academic fields with a sink or swim attitude, in the recommended first year graduate writing courses, an approach focusing on the power of negotiation should be embraced. Fujioka (2014) argues for the influence of active negotiations between the professors and the students over a writing assignment given and suggests that these negotiations can indeed shape the participants' academic practices in the present and future in multiple ways. Through open negotiations in 
those classrooms, instructors can see the underlying reasons for students' choices regarding linguistic, thematic and rhetorical moves and thus provide feedback accordingly. The written feedback given to especially international graduate students should move beyond the language use towards more on the content, organization and even the rhetorics because providing feedback on only language-related issues at the sentence level can cause students' question themselves as L2 writers in their academic communities (Séror, 2014), and therefore delay their full participation or engagement in the academic conversations. In Abigail's case, she wanted both the language-related feedback and the content and organization, and that was what she got from her professor because they had negotiated that at the beginning stages of their time in that course. Since there had been an agreement established between the student and the professor in that case, there was no tension later on. Abigail seemed to be willing to appropriate her academic discourse by also following the guidelines as precisely as possible as she saw that way as 'essential for academic success' (White, 2011 in Kobayashi et al. 2017, p. 244). However, in Orsi's case, she rejected making certain revisions on the content- about her experiences- because she believed that it was part of her emerging scholarly self that she was beginning to establish through her voice in her first high-stakes writing assignment. In her case, the negotiation with the professor had not taken place yet, but she seemed determined that she would not make the suggested changes to her writing.

\section{Support group meetings}

To accompany or as a replacement for such a graduate level course in the first year for academic literacy training and for negotiation, what institutions can also have or create the room for is a support group consisting of fellow graduate students that meet weekly or monthly to talk 
about their experiences in their first year as graduate students. Even though such meetings already happen organically, it could be more beneficial to have them in a more structured way. The focus of these meetings can range from challenges encountered in coursework or teaching to sharing of academic work or news about sources of academic involvement such as conferences or call for papers. In my first year as a master's student, we had weekly cohort meetings where we mainly talked about our teaching in the first-year writing program, with our team leader who was also a graduate student but more experienced than us in the program. Every week, we shared both the good stories we had gathered and also the challenges we encountered and we listened to each other and provided support. Seeing that we, as first year graduate students, were not the only ones dealing with the complexities of graduate school or teaching maybe for the first time motivated us more to invest in academic conversations and socialization practices. From my experience, I can tell that having such a support group has a very good potential to be beneficial. How these meetings can be structured depending on the needs of the graduate students, international or not, or the discipline-related policies and resources, for sure, but even an informal support group can go a long way in encouraging of involvement in the academic spaces for graduate students to navigate their identity performances in the academic discourses they are becoming a part of. To this end, they can better negotiate their changing/evolving identities as students into scholars in their fields, as Morita (2009) states, such out-of-class conversations and collaborations can make learning in academic spaces/disciplines and socialization easier.

\section{Writing center support}

To further support graduate students and their specific academic and disciplinary writingrelated needs to accompany their academic socialization practices, writing centers on campuses 
are usually considered as a go-to resource. Therefore, Abigail's first choice for writing support was also the writing center in her institution in her first semester. These centers, though, may not always be equipped to cater to the needs of graduate students and they may mainly work with undergraduate student profile, which was the case in Abigail's case. When it comes to international students, they may tend to provide help with only language-related matters and ignore the rhetorical needs emerging from the difference in the expectations of the western style writing in the disciplines. During the initial contact with the texts written by second language writers, tutors in the writing centers can form certain assumptions about the writers themselves or the texts they have produced; tutors who are not familiar with the ways some international students might produce texts with metaphors or figurative language that shows their richness through hybridity and alternatives may tend to be drawn to surface-level issues and mark them as problematic instances in writing (Matsuda and Cox, 2009). However, it is highly important to not see such divergences from one's own understanding of how language works as deficiency as these writers can already be proficient writers in other languages or genres.

One way of better supporting international graduate students' writing-related needs, then, would be to provide spaces for negotiation, especially in writing centers. Ortmeier-Hooper (2013) emphasizes the 'conversation-based approach to writing' (p.159) for successful negotiation of meaning in writing centers that can be especially beneficial to international students who face certain challenges as they transition to graduate school as well as an unfamiliar academic space from what they have seen in their countries or institutions where different languages may have been used for medium-of instruction and hence had different expectations. Minett (2009), to this end, suggests 'an open discussion about contrastive rhetoric' (p. 68) as it can help ESL writers understand English rhetoric and some of the presumptions they 
bring to writing, maybe even unconsciously. Such open conversations, Minett continues, can help 'make clear how English conventions and audience expectations are' though with an emphasis that no one way is better than the other but just different (p. 68). However, it is also the case that sometimes international students can themselves ask for explicit grammar or sentencelevel suggestions, leaving tutors feel more like 'intruders than collaborators' when they are asked to not focus on the whole text (Staben and Dempsey Nordhaus, 2009, p. 78). Therefore, it becomes crucial to have a 'talk before text' with the students who come for help with their writing as it shows the 'strength of writing center conferences' where extensive and individuallyoriented interactions can take place to benefit the students to the fullest (Staben and Dempsey Nordhaus, p. 81).

There are certainly higher education institutions that have sufficient resources and spaces to have tutors specifically trained to work with international students (For example, John S. Knight Institute for Writing in the Disciplines of Cornell University offers Graduate Writing Services (GWS); or Princeton Writing Program working with the Writing Center); however, it is also common to see that writing centers tend to mostly work with undergraduate students. In that sense, in our interviews, Abigail stated that she really needed some extra writing support during her first semester while they were completing their proposals for their theses, a high-stakes writing project, and therefore she went to the writing center at her university only to be told that they could not help her as she was a graduate student. Therefore, depending on available resources and funding, of course, training some graduate students to work with graduate students in these centers can result in more effective writers who can learn from fellow graduate students who are already familiar with the academic expectations in their prospective fields and who have been through similar challenges and processes. University of California at Davis has been using 
a tutoring service called Graduate Writing Fellows successfully since 2007 with trained $\mathrm{PhD}$ students in writing pedagogies (Ferris and Thaiss, 2011). The help students can get in similar spaces would not be limited to only language use, as we tend to see in ESL tutoring sessions usually, but can also include support on issues related to rhetorical moves, genre conventions and organizational and even thematic preferences in these tutoring sessions, depending on the needs of each student. In the Writing Center of the Academic Success Center at UC Davis, apart from one-on-one tutoring sessions with students, they also provide the opportunity to workshop on topics such as 'research/term paper, in-class exam writing, and style and grammar' (Ferris and Thaiss, p.11). For tutors who are to work with second language writers in such centers, Bruce (2009) lists tips for getting started and he specifically emphasizes the following:

- Finding out what the student already knows about the writing center and how tutoring works in that specific context,

- Asking about student's piece of writing to draw comments from the writers themselves that could be helpful in planning out the session,

- Asking even more direct questions if necessary regarding the writing assignment requirements to have students think deeper about the expectations,

- Setting goals about the one-on-one session together with the student and making the plan visible through lists, outlines, or visual maps etc.

However, Bruce also warns the tutors about being flexible and taking the plan as only a guide throughout the session. He also adds that students should be reminded of another use of the plan made together that could serve as a guide to have future revisions on the text on their own. Having these one-on-one sessions with specific foci, not only for American students but also specifically addressing international students, could benefit many who struggle to get acquainted 
with English academese on campuses where the number of international students are relatively high as well as for students who are in the minority profile.

To make sure that these multilingual students can still retain their voices in their writing in English as a second or additional language, though, too much appropriation should be avoided in these sessions. As Severino (2009) recalls her own experiences in writing in Italian as an exchange student, she cautions writing tutors for second language writers as to not make too many changes or suggestions to make the writing piece sound like themselves rather than the writers. Even though her writing experiences with Italian then was not high-stakes writings like the ones we see in writing centers in the US universities where a lot of international students are studying to have a degree, 'the pressure and challenges' might drive these international students 'to trade some of their voice for accuracy, idiomaticity, and increased language learning.'

(Severino, p.56). To this end, what the tutors dealing with students like these can do is that they can have the open conversation and negotiation a conferencing model offers at the beginning of the sessions and plan the time they will have together according to the needs and desires of the students who come to the center for different reasons- be it for sounding 'native', for being completely grammatically accurate or having an alternative way of expressing themselves in their second language of English.

\section{Professional trainings}

Another institutional support can come in the form of professional trainings for professors and graduate teaching assistants working with international students across disciplines as well as graduate teaching assistants working at First Year Writing Programs. In that sense, what writing centers do to provide support to students across campus is very much related to Writing Across 
Curriculum (WAC) programs that 'promote faculty involvement in the writing culture' (Ortmeier-Hooper, 2013, p.160). Since some instructors may not have the expertise about multilingual and multicultural writing across disciplines, it might be difficult for them to recognize the purposeful choices made by their students. Cooperation of instructors across disciplines on campus, therefore, especially one between the second language writing scholars with WAC professionals, would offer several benefits, as Hall and Navarro (2011) suggest, including but not limited to a better understanding of complex linguistic backgrounds of multilingual students and writers through the lenses of multicompetence theory (Cook, 1992), a research area focusing on the relationship between discipline-specific writing and second language acquisition and writing, and the deeper exploration of the concepts such as translinguality. To address cultural and linguistic diversity, either through annual trainings across disciplines or in-house discipline-specific second language writer focused training sessions by scholars in the faculty of education or learning and teaching centers-if available on campus, a broader collaboration can be sustained. These trainings can provide the instructional faculty with the necessary background knowledge on how to address the needs of multilingual students who are trying to produce academic texts in their disciplines. Having some foundational knowledge on how these resourceful individuals make linguistic and rhetorical choices in their writing can help the faculty provide better feedback and response to their engagement in academic literacy practices. (For more faculty resources to be utilized for and about multilingual graduate student writing, see Appendix D) 


\section{Instructional Support}

\section{Academic socialization of international students}

Creating such platforms and spaces to support student participation is not only the responsibility of the institutions. Any instructional faculty, from full-time professors to graduate teaching assistants who have international students in their classes, whether these are first-year writing courses in the English department or any other disciplinary course from first year to senior to master's to doctoral level, which involve academic writing, should also take part in making sure the multilingual students can represent their stance and voice in academic spaces they are a part of.

For instance, Seloni's (2012) study on academic literacy socialization of first yeardoctoral students in the US also showed that international students found it more challenging to participate in academic activities in doctoral classes than the native speaker students, which reminded me of what Abigail mentioned during one of our interviews- that how she keeps quiet during in-class conversations for fear of not being clear in what she says due to time limitations and respect for others' time. That's why, she told me, she likes writing as she has more time to express what she wants to say clearly enough. She also stated that some of the readings they did in her courses were too dense to understand for her and that she took more time to decipher them than her native speaker friends, suggesting that scholars writing those materials should take into consideration the needs of the second language users of English. In that sense, I would also agree with her because academic literacy is a different language of its own, a different register even, that even native speakers can have difficulty comprehending dense texts, but for international students, it may become double-challenging to participate and make their voices heard. Language socialization theory, in that sense, suggests that learning of a language comes with 
learning of ideologies, '[....] identities or subjectivities, affective orientations, linguistic and nonlinguistic content [....] and practices valued by the local community.' (Ochs, 1986 in Duff, 2010, p. 173). Therefore, Duff (2010) suggests that social positioning and engagement of oneself is a complex phenomenon that includes varying degrees of investment, agency, and negotiation of power relations and identities by the participants, that may result in ways to conform to the existing rules, norms and practices or resistance to them. Zappa-Hollman (2007) also suggests the same notion of complexity of academic socialization of non-native English speakers in graduate spaces through her study of six Mexican students where she analyzed the coping strategies of these international students in an English-medium university in Canada. In her study, she found that even for linguistically proficient students, academic socialization is a challenging task as their 'home academic discourse values' might be different from what is being expected of them in this new academic contexts and that they may resist the new values presented to them.

Soltani's (2018) study of participation patterns of users of English as a second language in different academic spaces shows how valuable it is to create that welcoming atmosphere. Soltani observed how his subject of study changed his participation and involvement in academic spaces from when he was in EAP course, where he was highly active, to his first mainstream course where he was mostly silent, and then to his second mainstream social space - in class and online platforms- where he was showing a mix of silent and active participation patterns. To this end, as in the case of Soltani's participant, using an online platform, forum postings or even Facebook groups for certain courses where students can participate in written academic conversations but in a more informal manner, can increase the likelihood of participation from multilingual or international students who may find the in-class and face-to-face conversations 
more challenging. Orsi, for example, also uses Facebook to talk about her beliefs and frequently posts about her ideas on social justice issues. Having used such a platform to have conversations, even from people outside of academia, has given her the confidence to pursue a similar attitude in her thesis proposal writing where she is confident in her arguments and supports what she believes fiercely- unlike her choice of keeping silent in conversations with friends who can be rather harsh. Zappa-Hollman and Duff (2015), thereby, offer the term individual networks of practice (INoP) to refer to 'multifaceted social dimensions and relationships that underpin learning that combines an analysis of individual competence and resourcefulness and the larger social system in which the individual is embedded.' (p. 339). INoP, then, centralizes the learner in the socialization process and takes into account all the interactions the learner engages in through linguistic and discursive practices (Zappa-Hollman \& Duff, p.334). Therefore, I believe that, a mix of formally and informally structured, both in-class and outside of class platforms can be made available for international graduate students to engage in scholarly conversations to increase the amount of their participation and investment in academic socialization and social networking practices.

\section{Writing workshops for peer response and feedback}

One of the ways to ensure or at least encourage support for multilingual student engagement is offering space for peer response and feedback. Along with forums posts and other online participation tools where each student can see and contribute to one another's work or ideas outside of class time, instructors can also create in-class activities to allow for voices from the fellow graduate students on each other's written artefacts in addition to instructor feedback. Au and Raphael (2010) suggest the use of writing workshops for ELL students where they can 
get to 'engage is authentic, purposeful, and meaningful to each student individually' (p.208).

During these writing workshops, each student can either work on a different stage of a writing assignment, or what could be better structurally for a graduate level course is having students to focus on one aspect of the same writing assignment each week, a high-stakes writing, and give each other responses based on the covered guidelines or the expectations of the rhetorical situation or the professors as well as the disciplinary conventions. This was exactly what I appreciated the most with Orsi and Abigail's experiences in their first-semester course focusing on thesis proposal writing in their department. Each week, they would focus on one part of the proposal after reading and discussing what each part is supposed to do based on the book they were following as a whole class. After creating their drafts, they would bring it to class and get into groups to discuss each and every one of their drafts before or after the professor's response to them. That way, they not only got feedback in a low-pressure space, but they would also get different kinds of response as each of their fellow graduate friends focused on different aspects of their writing. Such settings where a multiplicity of responses are provided 'have the potential to influence a writer's understanding of writing and of written texts' (Tardy, 2009, p.48), especially for those students who are still trying to figure out the new and unfamiliar ways of producing writing in an academic setting. For students who may not feel comfortable or confident enough to give oral feedback on the spot, Ortmeier-Hooper (2013) suggests asking students to have a written response first that could ease spoken communication later on, or for students who might lack the meta-language about writing, language, and rhetoric, we can also have introductory sessions before practicing peer response. At the end, the students would be able to complete a multi-phased, complex and high-stakes writing assignment in their discipline without being overwhelmed. Even though not in every course such a semester long 
workshopping can be given space, even if instructors can dedicate one class hour to such peer response session, it would benefit the students who may not be familiar with the expectations of writing in their disciplines. In addition, since professors may not be able to have time to individually negotiate with each student about every writing assignment they have, peer response workshops can also alleviate some of responsibilities of the instructors by addressing the major problematic areas in students' writing before they start grading the final drafts. This way, by sharing their ideas and opinions on fellow students' work, students can also see themselves 'as members of the social network in their academic discourse' (Au and Raphael, 2010, p. 209), which in turn, affects how easily they can socialize in academic spaces and embrace their scholar identities, moving away from the 'just a student' role.

\section{Room for creative and alternative expressions}

In addition to workshopping and peer response activities, even if not in big scales, instructors teaching students with varying linguistic and cultural backgrounds can also allow for creative expression in writing as a way of encouraging individuality and agency of their students in their identity and voice representations. Tardy (2016) states that moving away from 'generic forms' could be a way to exert one's authorial identity, a way to assert one's individuality (p.34). She also argues that typically academic writers are invested in meeting the demands of their readers, but when we do see departures from the expected norms, we should investigate the whys of these moves (p.50-51). Innovation in academic genres, according to Tardy, hence, could be ideational- 'to stand out' (p.51), or 'interpersonal'- in order to engage with the readers (p.57). In that sense, Murat's readability concern and therefore making choices to include a narrative style into his academic texts represents his way of bending the rules of research article genre, which 
shows his creativity. For Orsi, not conforming to the suggestions of her professor telling her to cut down on her experiences to support her claims in her thesis proposal shows how she is willing to stretch the conventions or expectations from her reader to represent herself or take 'ownership' of her writing in that genre (Tardy, p.58).

The individuality of multilingual writers can be observed in many ways, including but not limited to, acts regarding language use, genres, content, rhetorics, themes or even research methods. To account for the need for room for genre innovation, Tardy (2016), drawing from Blommaert (2010), states that to align with the 'diversity and mobility that characterize $21^{\text {st }}$ century' (p.18), approaches to language and discourse should be re-considered. Considering the linguistic diversity in our classrooms, too, allowing for the diversity in expression, in any way it comes as, becomes a need for the time period we are in. One way that diversity can show itself in our students' written work is genre innovation or genre play, as Tardy (2016) extensively talks about in her book. What I have also observed from all my participants in this study falls under this creative use of writing by these multilingual individuals. All three of my participants blend different styles in their writing; they bend the rules, conventions, expectations of the academic writing as they perceive them. Orsi insists on using her personal experiences despite her professor's comments; Murat uses a mix of narrative and facts in his articles, and Abigail starts her writing by first talking about her own experiences and existing knowledge to structure her paper. In this regard, they do what Robillard and Combs (forthcoming) call blended scholarship where, as Miller in the forward says '[this transformational scholarship] cuts across both literary forms and generic conventions; $[\ldots .$.$] and invites the reader to invent their own ways of$ generating writing that moves between the personal and the scholarly, the individual and the general, the specific and the universal' (ix). In that sense, by playing with the genre of academic 
writing, the writers in a way can assert their agency and that is what the participants in my study have done, and that is what I am actually trying to do, in the way $I$ take it up as, in my own writing of this master's thesis, thanks to the support I have form my academic advisor, who also talks about, in her blended essay, 'encourage[ing] openness to difference and patience to construct meaning and at some level willingness to connect with the felt sense [....]' (Seloni, forthcoming, p.98). As instructors teaching a diverse population of students, having the attitude

of openness to difference, whether it is in regards to genre innovation or language use, helps our students feed their willingness to participate. Seloni also recalls, in the same essay, how as a multilingual, transnational woman, she saw English academic writing as her 'ticket to success' (p. 106) in her early years as a graduate student and only came to see the importance of the personal recently, especially in her home field of applied linguistics and second language writing.

\section{Room for language play through translingualism}

Drawing from the theories surrounding translingualism, Seloni (forthcoming) problematizes 'the normative understandings of languages' and reminds the reader of how language difference should be seen as resource rather than interference (p.96). What Tardy (2016) calls language play or 'playful disruptions of language norms', to me, is very much in alignment with what translingualism argues for- the creativity in language use; all the linguistic resources multilinguals can use; all the linguistic resources monolinguals use; or moving away from definitions focusing on the number of languages towards a translingual one that emphasizes the moves within and across languages and their varieties. Translingual writers are, therefore, authors who can express themselves in 'multiple verbal systems' (Kellman, 1996). These 
systems could demonstrate a variety of unique expressions a writer can make use of to represent who they are, making the texts produced by these translingual writers negotiable. In that sense, Canagarajah (2013) describes translingual literacy as the activities surrounding text 'production, circulation and reception', an understanding which sees texts as mobile, which in turn requires 'inter-community negotiations' (p. 41). These negotiations can take place internally with the writer and between the writer and the reader. In its immediate context, the texts produced during graduate studies are primarily read by the professors. In cases of 'non-standard' usages or playful language use, then, instead of seeing such usages as errors to correct or deficiencies of the writers, what professors of translingual writers can do is to create room for explanation, exploration and negotiation. Through translingual approach to writing in broad sense, and to second language writing specifically, we can '(1) honor the power of all language users to shape language to specific ends; (2) recognize the linguistic heterogeneity of all users of language both within the United States and globally; and (3) directly confront English monolingualist expectations by researching and teaching how writers can work with and against, not simply within, those expectations.' (Horner et al, 2011, p.305). In short, then, languages are fluid, they are mobile and so they can be negotiable in any writing situation.

Orsi and Abigail had the chance to actually negotiate their writing with their professors in the course they were taking to write their thesis proposals. For Murat, he got written feedback on his weekly reviews from the professor. However, even though we did not have an explicit conversation about each and every dialogue they had with their professors regarding their linguistic choices in each of their papers, there were moments which created moments for me to consider their 'non-standard' usages of language in the academic texts they provided for the study. For instance, Murat mentioned how he sometimes uses foreign words/phrases in his 
writing when he cannot find the exact counterpart in English, be it an Ottoman Turkish word or a Latin one. And he said that it would usually attract readers' attention as it would break the reading patterns, or at least he was hoping that would be the case as he would do it himself as a reader of historical texts. For Abigail, even though we did not have an open conversation about it directly, when I looked at her writing sample, I realized that she sometimes has unusual usages of the pluralization. For example, in one instance, she used 'evidences' even though traditionally it is a mass noun and would not require a plural '-s', she did pluralize the word to maybe emphasize the amount of evidence. I acknowledge that it might have been a simple grammar mistake, but as an instructor reading that text, what I would do is to look for patterns in such divergent usages and bring it up for a discussion with the student to see the underlying reasons for it- to see if it was a one-time mistake or a purposeful usage to make a point. The same goes for Orsi's written artefact, as well. When I was looking for alternative expressions to usual norms in academic writing, I realized that in once instance she used the idiom 'pick up the slack'. I immediately remembered that she had said in one of our interviews that she would first write about a topic as if she is talking to get all her ideas out there, and then she would change the language or the register to make it more fit for an academic audience. Such a usage could be what remained from her change from informal to formal text or it might have been purposefully placed there to get her message across in a more efficient way. It seems to me that, such an instance would also require a conversation between the student and the instructor before marking them as errors or disregarding the possibility that it could be a way for these resourceful individuals to insert their ideas or stance into the text subtly.

Every translingual individual has diverse and broad repertoire of linguistic resources that have the capacity to be used creatively for self-expression and to be heard in a range of social, 
cultural and situational positions. As instructors, then, we need to provide spaces for language negotiation, especially regarding academic literacies, through one-on-one conferences as well as through 'constructed dialogue' to increase academic socialization (Baffy, 2016) and in order to make better use of the multicompetence our students have- monolingual or multilingual. Instead of disregarding a text or asking for major organizational revisions, for instance, we could talk to the students themselves about the reasons behind their choices that directed them to follow a certain way- which may not have aligned with instructor's expectations. When given the chance, the students can think critically and reflectively about their own choices as they may not even be aware of their own writing practices and such interactions could benefit them to be more aware of their writing patterns. In addition to such after-text dialogues, creating a session where the expectations of a writing assignment is explained clearly and in detail before they start writing could also prevent undesired linguistic outcomes later on. However, it should also be emphasized in these sessions that if students are going to be diverging from the expected linguistic norms, they should present their rationale behind it. Such rationale could be presented through uptake documents where students can document their learning and writing processes and in that way provide the reader, professor, a road map as to how the original document should be read. Accompanying the assignment with a rationale should not only empower the student who is exerting their linguistic identity but also the reader who may not be familiar with the varieties of the language(s) used. Having it communicated through writing should also ease the pressure of face-to-face communication with the professor, which might create anxiety among the less confident or more introverted students or for those who find it easier to communicate through writing than spoken communication, as in the case of Orsi and Abigail. Therefore, we should acknowledge that these students have already existing sets of skills and knowledge on how their 
languages work and how knowledge is constructed and distributed in academic spaces, even if they may not be aware of their resources themselves fully and thus not willing or able to openly take ownership of their diverse practices. Therefore, these dialogues that promote negotiation help increase collaboration among the faculty and students who are also emerging scholars themselves. Pratt (1998) uses the term 'contact zones' to refer to 'social spaces where cultures meet, clash and grapple with each other, often in contexts of asymmetrical relations of power [....].' (p.173). For fruitful collaboration, in that sense, those possible asymmetrical relations between the graduate students and the graduate faculty that may hinder an embodied representation of voice and identity should be reconsidered around the social roles as that of mentor and the mentee, because as Tardy (2009) illustrates through Dong's study conducted in 1998, second language writers, both at the master's and the doctoral level rely more on their advisors for support and suggestions (p. 204). In that sense, being the mentors to our students, especially to those who might need it more than their L1 counterparts, in the contact zones we can call our classrooms, we can provide the necessary instructional support, by not only allowing for creativity in genres and languages used, but also in the way identities and voices are represented that could be beyond our familiarity. 


\section{REFERENCES}

Agar, M. (2006). Culture: Can you take it anywhere?. International Journal of Qualitative Methods, 5 (2).

Allison, H. \& Harklau, L. (2010). Teaching academic literacies in secondary school. In G. Li \& P.A. Edwards (Eds.). Best Practices in ELL Instruction (pp 129-150). New York: The Guilford Press.

Anzaldúa, G. (2012). Borderlands. San Francisco, USA: Aunt Lute Books.

Aronson, J. (1995). A pragmatic view of thematic analysis. The Qualitative Report, 2 (1).

Retrieved on January $26^{\text {th }} 2019$ from

https://nsuworks.nova.edu/cgi/viewcontent.cgi?article=2069\&context=tqr

Au, K.H. \& Raphael, T.E. (2010). Using workshop approaches to support the literacy development of ELLs. In G. Li \& P.A. Edwards (Eds.). Best Practices in ELL Instruction (pp 207-221). New York: The Guilford Press.

Braun, V., Clarke, V. (2006). Using thematic analysis in psychology. Qualitative Research in Psychology, 3 (2), pp. 77-101.

Boroditsky, L. (2018, April 1 $\left.11^{\text {th }}\right)$. "How languages shape the way we think". YouTube. Retrieved on February $27^{\text {th }} 2019$ from https://www.youtube.com/watch?v=RKK7wGAYP6k.

Canagarajah, A. S. (1999). Resisting Linguistic Imperialism in English Teaching. Oxford: Oxford University Press.

Canagarajah, S. (2002). Geopolitics of Academic Writing. Pittsburgh: University of Pittsburgh.

Canagajarah, A. S. (2004). Subversive identities, pedagogical safe houses, and critical learning. In B. Norton \& K. Toohey (Eds.). Critical pedagogies and language learning. (pp 116-137). Cambridge, UK: Cambridge.

Canagarajah, A.S. (2013). Negotiating translingual literacy: An enactment. Research in the Teaching of English, 48 (1). pp 40-67.

Casanave, C.P. (2009). Training for writing or training for reality? Challenges facing EFL writing teachers and students in language teacher education programs. In Manchón, R. (Ed.). Writing in Foreign Language Contexts: Learning, Teaching, and Research. (pp 256280). Multilingual Matters. 
Celaya, M.L. \& Navéz, T. (2009). Age-related differences and associated factors in foreign language writing. Implications for L2 writing theory and school curricula. In Manchón, R. (Ed.). Writing in Foreign Language Contexts: Learning, Teaching, and Research. (pp 130156). Multilingual Matters.

Combs, S. \& Robillard, A. (Forthcoming). How Stories Teach Us. New York: Peter Lang.

Cook, V. (2002). Background to the L2 user. In V. Cook (Ed.). Portraits of the L2 user (pp 128). Clevedon, UK: Multilingual Matters Ltd.

Cook, V. (2008). Multi-competence: Black hole or wormhole for second language acquisition research? In Zhao Hong Han (Ed.). Understanding second language process (pp 16-26). Clevedon, UK: Multilingual Matters.

Croker, R. A.(2009). An introduction to qualitative research. In J. Heigham \& R. Croker (Eds.). Qualitative Research in Applied Linguistics: A Practical Introduction. (pp 3-24). UK: Palgrave Macmillan.

Davis, K. A. (1995). Qualitative theory and methods in applied linguistics research. TESOL Quarterly, 29 (3). pp 427-453.

Duff, P. (2008). Case Study Research in Applied Linguistics. New York: Routledge.

Duff, P.A. (2010). Language socialization into academic discourse communities. Annual Review of Applied Linguistics, 30. pp 169-192.

Eggins, S. (2004). An Introduction to Systemic Functional Linguistics (2 ${ }^{\text {nd }}$ Ed.). New York: Continuum.

Enrollment Report. (2018) Retrieved on January $20^{\text {th }} 2019$ from https://prpa.illinoisstate.edu/data_center/student/Spring\%202018\%20Enrollment\%20Repor t\%20Updated.pdf

Fang, Z. (2004). Scientific literacy: A systemic functional linguistics perspective. Science Education, 89, pp 335-347.

Fereday, J., Muir-Cochrane, E. (2006). Demonstrating rigor using thematic analysis: A hybrid approach of inductive and deductive coding and theme development'. International Journal of Qualitative Methods, 5 (1).

Ferris, D. \& Thaiss, C. (2011). Writing at UC Davis: Addressing the needs of second language writers. Across the Disciplines, 8 (4). 
Flowerdew, J. \& Li, Y. (2009). The globalization of scholarship: Studying Chinese scholars writing for international publication. In Manchón, R. (Ed.). Writing in Foreign Language Contexts: Learning, Teaching, and Research. (pp 156-183). Multilingual Matters.

Fujioka, M. (2014). L2 student-US professor interactions through disciplinary writing assignments: An activity theory perspective. Journal of Second Language Writing, 25. pp 40-58.

Gall, M.D, Borg, W.R, Gall, J.P. (1996). Educational Research: An Introduction (6 $6^{\text {th }}$ Ed.). New York: Longman Publishers.

Hall, J. \& Navarro, N. (2011). Lessons for WAC/WID from language learning research: Multicompetence, register acquisition, and the college writing student. Across the Disciplines, 8 (4).

Halliday, M.A.K (2013). An Introduction to Functional Grammar (3rd Ed.). New York: Routledge.

Harrison, K. D. (2007). When Languages Die: The Extinction of the World's Languages and the Erosion of Human Knowledge. Oxford: Oxford University Press.

Hatch, J. A. (2002). Doing qualitative research in education settings. Albany, New York: Suny Press.

Hirvela, A. \& Belcher, D. (2001). Coming back to voice: The multiple voices and identities of mature multilingual writers. Journal of Second Language Writing, 10, pp 83-106.

Holliday, A. (2015). Qualitative research and analysis. In B. Paltridge \& A. Phakiti (Eds.). Research Methods in Applied Linguistics. (pp 50-62). New York: Bloomsbury.

Horner, L., Lu, M., Royster, J.J., Trimbur, J. (2011). Language difference in writing: toward a translingual approach. College English, 73 (3), pp 303-321.

Hyland, K. 1998. Hedging in Scientific Research Articles. Amsterdam: John Benjamins.

Hyland, K. 2005. Metadiscourse. London: Continuum.

Hyland, K. (2008). Disciplinary voices: Interactions in research writing. English Text Construction, l (1), pp 5-22.

Institute of International Education, (2017). 'Enrollment', Open Doors Report on International Educational Exchange. Retrieved on January $20^{\text {th }} 2019$ from https://www.iie.org/en/Research-and-Insights/Open-Doors/Data/International$\underline{\text { Students/Enrollment }}$ 
Institute of International Education. (2018). 'International Students By Academic Level, 2016/2017-2017/18.' Open Doors Report on Institutional Educational Exchange. Retrieved on January $20^{\text {th }} 2019$ from https://www.iie.org/en/Research-and-Insights/OpenDoors/Data/International-Students/Academic-Level

International Statistics. (2018). Retrieved on January $20^{\text {th }} 2019$ from https://internationalstudies.illinoisstate.edu/students-scholars/about-isss/statistics/

Ivanic, R. \& Camps, D. (2001). I am how I sound: Voice as self-representation in L2 writing. Journal of Second Language Writing, 10. pp 3-33.

Jome, E. (2018, September 5). Freshman and graduate student numbers up at Illinois State. Retrieved on January $20^{\text {th }} 2019$ from https://news.illinoisstate.edu/2018/09/freshman-andgraduate-student-numbers-up-at-illinois-state/

Kachru, B. B. (1985). Standards, codification, and sociolinguistic realism: The English language in the outer circle. In Quirk, R. and H. Widdowson, (Eds.). English in the World: Teaching and Learning the language and the literature. Cambridge: Cambridge University Press.

Kellman, S. G. (1996). J. M. Coetzee and Samuel Beckett: The Translingual Link. Comparative Literature Studies, 33 (2), pp 161-172.

Kobayashi, M. (2016). L2 academic discourse socialization through oral presentations: A Japanese undergraduate student's learning trajectory in study abroad. The Canadian Modern Language Review, 72, 95-121.

Kobayashi, M., Zappa-Hollman, S., Duff, P.A. (2017). Academic discourse socialization. Language Socialization, Encyclopedia of Language and Education. pp 239-254.

Lazaraton, A. (1995). Qualitative research in applied linguistics: A progress report. TESOL Quarterly, 29 (3). pp 455-472.

Litosseliti, L. (2010). Research Methods in Linguistics: Second Edition. UK: Bloomsbury.

Manchón, R., \& de Haan, P. (2008). Writing in foreign language contexts (Editorial). Journal of Second Language Writing, 17 (1). pp 1-6.

Manchón, R., De Larios, J., Murphy, L. (2009). The temporal dimension and problem-solving nature of foreign language composing processes. Implications for theory. In Manchón, R. (Ed.). Writing in Foreign Language Contexts: Learning, Teaching, and Research. (pp 102130). Multilingual Matters. 
Matsuda, P. K. (2001). Voices in Japanese written discourse: Implications for second language writing. Journal of Second Language Writing, 10. pp 35-53.

Matsuda, P. K. (2006). The myth of linguistic homogeneity in U.S. college composition. College English, 68 (6). pp 637-651.

Matsuda, P.K. \& Tardy, C.M. (2007). Voice is academic writing: The rhetorical construction of author identity in blind manuscript review. English for Specific Purposes, 26. pp 235-249.

Matsuda, P.K. \& Tardy, C.M. (2008). Continuing the conversation on voice in academic writing. English for Specific Purposes, 27. pp 100-105.

Matsuda, P.K. \&Cox, M. (2009). Reading an ESL writer's text. In S. Bruce and B. Rafoth (Eds.). ESL Writers: A Guide for Writing Center Tutors. (pp. 42-50). Portsmouth, NH: Heinemann.

McKay, M. (2013). Language, identity, power relations and discourse: A cree language response to linguistic imperialism. Native Studies Review, 22 (1\&2). pp 27-53.

Merriam, S. B. (1998). Qualitative Research and Case Study Applications in Education. Revised and Expanded from "Case Study Research in Education". San Francisco: Jossey-Bass Publishers.

Minett, A.J. (2009). 'Earth Aches by Midnight': Helping ESL writers clarify their intended meaning. In S. Bruce and B. Rafoth (Eds.). ESL Writers: A Guide for Writing Center Tutors. (pp. 66-77). Portsmouth, NH: Heinemann.

Morita, N. (2004). Negotiating participation and identity in second language academic communities. TESOL Quarterly, 38. pp 573-603.

Morita, N. (2009). Language, culture, gender, and academic socialization. Language and Education, 23 (5). pp 443-460.

Nero, S. (2005). Language, identities, and ESL pedagogy. Language and Education, 19 (3). pp 194-211.

Nieto, S. (2004) Culture, identity, and learning. In. Nieto, S. \& Bode, P. (Eds.). Affirming Diversity. The Sociopolitical Context of Multicultural Education. (pp 144-164). Boston: Pearson.

Norton, B. (2000). Social identity, investment and language learning. TESOL Quarterly. 29 (1). pp 9-31. 
Norton, B. (2010). Language and identity. In N. Hornberger and S. McKay (Eds.). Sociolinguistics and Language Education, pp 349-364. UK: Multilingual Matters.

Olsen, L. (1998). Teaching and researching thesis/dissertation in ESP. Colloquium Introduction. Seattle: TESOL 1998.

Ortega, L. (2009). Studying Writing across EFL contexts: Looking back and moving forward. In Manchón, R. (Ed.). Writing in Foreign Language Contexts: Learning, Teaching, and Research. (pp 232-255). UK: Multilingual Matters.

Ortmeier-Hooper, C. (2013). The ELL Writer: Moving Beyond Basics in the Secondary Classroom. New York: Teachers College Press.

Pavlenko, A., \& Lantolf, J. P. (2000). Second language learning as participation and the (re)construction of selves. In Lantolf, J. P. (Ed.). Sociocultural Theory and Second Language Learning. (pp155-177). Oxford: Oxford University Press.

Pennycook, A. (1994). The Cultural Politics of English as an International Language. UK: Routledge.

Phillipson. R. (1992). Linguistic Imperialism. Oxford: Oxford University Press.

Pratt, M.L. (1998). Arts of the contact zone. In V. Zamel \& R. Spack (Eds.). Negotiating Academic Literacies. (pp 171-185). New Jersey: Lawrence Erlbaum Associates Publishers.

Prior, P. (2001). Voices in text, mind, and society: Sociohistoric accounts of discourse acquisition and use. Journal of Second Language Writing, 10. pp 55-81.

Reichelt, M. (2009). A critical evaluation of writing teaching programmes in different foreign language settings. In Manchón, R. (Ed.). Writing in Foreign Language Contexts: Learning, Teaching, and Research. (pp 183-206). UK: Multilingual Matters.

Rinnert, C. \& Kobayashi, H. (2009). Situated writing practices in foreign language settings: the role of previous experiences and instruction. In Manchón, R. (Ed.). Writing in Foreign Language Contexts: Learning, Teaching, and Research. (pp 23-49). UK: Multilingual Matters.

Robertson, W. (2010). "Writing Across Borders". Writing Center, Oregon State University. Retrieved on February $20^{\text {th }} 2019$ from http://writingcenter.oregonstate.edu/writing-acrossborders. 
Sasaki, M. (2009). Changes in English as a foreign language students' writing over 3.5 years: A sociocognitive account. (pp 77-102). In Manchón, R. (Ed.). Writing in Foreign Language Contexts: Learning, Teaching, and Research. UK: Multilingual Matters.

Seliger, H. W., Shohamy, E. (1989). Second Language Research Methods. Oxford: Oxford University Press.

Seloni, L. (2012). Academic literacy socialization of first year doctoral students in US: A microethnographic perspective. English for Specific Purposes, 31. pp 47-59.

Seloni, L. (2014). 'I'm and artist and a scholar who is trying to find a middle point': A textographic analysis of a Colombian art historian's thesis writing'. Journal of Second Language Writing, 25, pp 79-99.

Seloni, L. (Forthcoming). Moving literacies. In S. Combs and A. Robillard (Eds.), How Stories Teach Us. pp 93-108. New York: Peter Lang.

Séror, J. (2014). Or, just it's my fault?: Language socialization through L2 writing feedback. In J. S. B. Clark \& F. Dervin (Eds.), Reflexivity in Language and Intercultural Communication: Rethinking Multilingualism and Interculturality (pp. 64-80). New York: Routledge.

Severino, C. (2009). Avoiding appropriation. In S. Bruce and B. Rafoth (Eds.). ESL Writers: A Guide for Writing Center Tutors. (pp. 51-65). Portsmouth, NH: Heinemann.

Shanti, B. (2009). Breaking ice and setting goals: Tips for getting started. In S. Bruce and B. Rafoth (Eds.). ESL Writers: A Guide for Writing Center Tutors. (pp. 33-41). Portsmouth, $\mathrm{NH}$ : Heinemann.

Soltani, B. (2018). Academic socialization as the production and negotiation of social space. Linguistics and Education, 45. pp 20-30.

Staben J.E. \& Dempsey Nordhaus, K. (2009). Looking at the whole text. In S. Bruce and B. Rafoth (Eds.). ESL Writers: A Guide for Writing Center Tutors. (pp. 78-90). Portsmouth, NH: Heinemann.

Talmy, S., Richards, K. (2011). Theorizing qualitative research interviews in applied linguistics. Applied Linguistics, 32 (1). pp 1-5.

Tardy, C. (2009). Building Genre Knowledge: L2 Writing. United States: Parlor Press.

Tardy, C. M. (2016). Beyond convention: Genre innovation in academic writing. US: University of Michigan Press ELT. 
Qualitative Research: Case Study Guidelines. (2019). TESOL International Association. Retrieved on February $15^{\text {th }} 2019$ from https://www.tesol.org/read-andpublish/journals/tesol-quarterly/tesol-quarterly-research-guidelines/qualitative-researchcase-study-guidelines

Yamada, K. (2016). Cross-disciplinary variations: Japanese novice writers' socialization into the undergraduate thesis. The Asia-Pacific Education Researcher, 25 (2). pp 207-217.

You, X. (2004). The choice made from no choice: English writing instruction in a Chinese University. Journal of Second Language Writing, 13, pp 97-110.

You, X. (2004). New directions in EFL writing: A report from China. Journal of Second Language Writing, 13, pp 253-256.

Zappa-Hollman, S. (2007). Academic presentations across post-secondary contexts: The discourse socialization of non-native English speakers. The Canadian Modern Language Review, 63 (4). pp 455-485.

Zappa-Hollman, S. , Duff, P.A. (2015). Academic English socialization through individual network of practice. TESOL Quarterly, 49 (2). pp 333-368. 


\section{APPENDIX A: PRE-INTERVIEW SURVEY}

The goal of this study is to investigate and understand how multilingual writers in graduate schools in the US write in their disciplinary courses in English as a second language. In that sense, the study will mainly focus on your academic writing practices in English in your discipline and how your prior experiences in academic writing in other languages and in different contexts shape your linguistic choices in the US with regards to the representations of your multilingual identities and voices. Drawing from the information gathered through multiple interviews and analysis of an academic writing sample, equitable and accessible writing instruction suggestions will be made to meet the needs of writers like yourself in the academic settings. In that sense, it is very important that you respond in as much detail as possible to the following questions- as well as during the interviews.

1. Date of Birth:

2. Gender and sexual orientation:

3. Country of origin:

4. Your first language(s)/mother tongue(s):

5. Additional languages, situations you use them and the purposes:

6. Current area and degree of study in the US:

7. Educational background:

8. Time spent in the US:

9. Places lived prior to US:

10. Work experience:

11. Future work / study plans: 
12. Which genres are you familiar with writing? Think about BOTH school AND out of school contexts. For instance, for out of school genres, you can list online blog or forum posts, journal writing, Instagram posts, or even memes. For school genres, you can think of thesis proposals, research papers, conference proceedings etc. Make TWO different lists.

School genres:

Out of school genres:

13. What kind of genres do you typically produce in your field?

14. What are the most and least favorite things you experience while writing. List at least 3 for both most and least favorite aspect for you. 


\section{APPENDIX B: FIRST INTERVIEW QUESTIONS}

The purpose of the first interview is to gather information about the writing practices in general, then academic writing practices specifically, and lastly writing in their disciplines.

\section{Writing practices in general}

- Do you enjoy writing in general- in any language you know/use?

- What are some of the reading and writing activities you engage in on a daily basis/regularly as a graduate student? (In your first or second language, English) Can you list the genres in which you write for school purposes? For instance, thesis proposal, grant proposals, research papers, conference call for papers, abstracts etc.

- Can you also list the genres you write in for other purposes and contexts? For instance, online posts, comments on blogs, diary entries, email exchanges etc.

- Do you feel free or limited do you feel in these genres in terms of your choices? If so, in what ways? What makes you feel that way? How do you negotiate it- do you conform or deviate from the requirements? How? Why?

- Do you think you are a good writer in your first language? What makes a good writer do you think in your first language and in different genres that you listed earlier?

\section{Academic writing related}

- How did you learn academic writing style? In home country? In your first language?

- How did you learn academic writing in English? For instance, I studied in an Englishmedium university back in Turkey and until the prep year, I had no idea how to write academic papers or essays in my first language.

- Do you think academic writing is different in your first language and in English? Have you done any academic writing in your first/other languages? F so, what kind of writings 
were they? Compared to academic English writing, how difficult/different was it? In what ways?

- How do you think your experiences with writing in L1 or other languages or other genres you have listed before influenced your academic writing in English in graduate school here? Any positive or negative influences, transfer of skills and strategies you can think of?

- What do you think your weaknesses and strengths in writing in English?

- What are the processes that you go through before/while/after you write (in terms of research-asking for help-reviewing your work etc.) in (academic) English?

- Do you feel any tension/challenge while composing academic texts? Why do you think so? How do you react to those situations?

- What is the most challenging part of writing in (academic) English? Do you think you were well-prepared before starting your graduate studies in the US?

\section{Discipline-related writing questions}

- In what genres do you usually write in your disciplinary area? How often do you write for academic purposes? What genres are prioritized in your courses?

- What sort of writing tasks do you usually encounter in the academia?

- What are the most important academic writing skills do you think you should have in your discipline?

- What writing knowledge/skill do you think someone in your major should have before they graduate?

- What do you think the role of writing is in your discipline? 
- What constitutes a well-written academic writing for you? Or how do you define a good (academic) writer in your field? 


\section{APPENDIX C: SECOND INTERVIEW QUESTIONS}

\section{Identity and Voice related questions via discursive and non-discursive features}

- How do you usually form your sentences and organize your whole academic texts? Think about the paragraph structures, specific word and phrase choice, transitions, sign postings etc.

- How about the content of your papers? How do you usually decide on your research topic maybe when it is not given by the professor? What is your writing process like then?

- How do you form arguments in your papers? What does your use of language look like when you are arguing, supporting, or criticizing?

- How do you make use of other texts within your writing? (intertextuality) What are some of your strategies when paraphrasing or quoting someone else's work?

- Do you think about audience when you compose your academic texts? How does it (if so) influence the way you write? Think about from word level issues to whole text.

- How do you usually decide on what font to write in? How about punctuation and spacing between paragraphs? What does a usual paper you write in your field look like? Think about paragraphs, direct quotations or page layout.

- Based on the answers you have given, how do you think you are positioning yourself within the texts you are writing in your field?

- Do you think you can easily represent your writer identity within your writing through these (textual) choices you make?

- Do you think our identities play a role in how we write for different purposes? How?

- Do you think you have found your voice in writing in English? If so, how do you demonstrate it in your writing- in different writing situations? 


\section{Questions specific to the writing samples:}

- How would you categorize the type of writing in terms of its genre?

- How did you decide on the topic of this paper?

- What does this assignment ask you to do?

- Have you done similar writing assignments before- in your other languages? Are there any similarities/differences between them?

- What would you have done differently with this paper if it was in another language (your first language)? Why?

- How did you compose this piece of writing? (before-during-after practices you engaged in) What were some of the specific decisions you made when composing this piece of writing- especially in terms of words and phrases or grammatical structures?

- What are some of the challenges you faced while composing this writing? Do you think you were able to make your identity visible in your writing or did you want it to be visible?

- How long did it take you to write this? Is it usual?

- If you were to write this paper in any of the other languages you know, what would have been different? What would you have done differently during the process?

- Are there any changes you would like to see- especially in terms of the writing assignments that you usually get or the instructor feedback?

- How (if any) did you 'play' (changed/diverged from) with the expectations/requirements of the assignment? Why did you choose to do so? How exactly did you do it? Explain. If you didn't, why? 


\section{APPENDIX D: FACULTY RESOURCES FOR MULTILINGUAL GRADUATE STDUENT}

\section{WRITING $^{6}$}

Bailey, S. (2015). Academic writing for international students of business (2nd ed.). Routledge.

Canseco, G. (2010). Inside academic writing: Understanding audience and becoming part of an academic community. Ann Arbor: University of Michigan Press.

Caplan, N. A. (2012). Grammar choices for graduate and professional writers. Ann Arbor: University of Michigan Press.

Cargill, M., \& O'Connor, P. (2013). Writing scientific research articles: Strategy and steps (2nd ed.). Oxford: Wiley-Blackwell.

Curry, M. J., \& Lillis, T. (2013). A scholar's guide to getting published in English: Critical choices and practical strategies. Bristol: Multilingual Matters.

Feak, C., Reinhart, S. M., \& Rohlck, T. N. (2009). Academic interactions: Communicating on campus. Ann Arbor: University of Michigan Press.

Feak, C., \& Swales, J. M. (2009). Telling a research story: Writing a literature review. Ann Arbor: University of Michigan Press.

Feak, C., \& Swales, J. M. (2011). Creating contexts: Writing introductions across genres. Ann Arbor: University of Michigan Press.

Swales, J. M., \& Feak, C. (2000). English in today's research world: A writing guide. Ann Arbor: University of Michigan Press. [Note: the revised and expanded edition is published in four separate volumes, listed here]

Swales, J. M., \& Feak, C. (2009). Abstracts and the writing of abstracts. Ann Arbor: University of Michigan Press.

Swales, J. M., \& Feak, C. (2011). Navigating academia: Writing supporting genres. Ann Arbor: University of Michigan Press.

Swales, J. M., \& Feak, C. (2012). Academic writing for graduate students: Essential tasks and skills (3rd ed.). Ann Arbor, MI: University of Michigan Press.

Wallace, M., \& Wray, A. (2011). Critical reading and writing for postgraduates ( $2^{\text {nd }}$ ed). London: SAGE.

\footnotetext{
${ }^{6}$ Compiled from the resources available at Consortium on Graduate Communication: https://www.gradconsortium.org/resources/
} 